\title{
Does the Investment-Based Model Explain the Value Premium? Evidence from Investment Euler Equations*
}

\author{
Stefanos Delikouras $^{\dagger} \quad$ Robert F. Dittmar ${ }^{\ddagger}$
}

March 2011

\begin{abstract}
We empirically investigate the ability of stochastic discount factors rooted in the investmentbased pricing theory to explain differences in equity risk premia across book-to-market-sorted portfolios. Our approach to this question is to specify the stochastic discount factor as lying in the linear span of firms' investment returns. In contrast to previous theoretical results, we find that the model cannot empirically generate a value premium. However, our results indicate that this result is not due to the inability of the model to generate cross-sectional variation in risk across book-to-market-sorted portfolios. Value firms are riskier than growth firms, but the risk premium needed to generate the observed value premium is larger than can be generated by the investment-based model.
\end{abstract}

\footnotetext{
${ }^{*}$ The authors would like to thank Erica Xuenan Li and Chen Xue for helpful comments and discussions. All errors are the responsibility of the authors.

${ }^{\dagger}$ Department of Finance, Stephen Ross School of Business, University of Michigan, Ann Arbor, MI 48109, email: sdeli@umich.edu

${ }^{\ddagger}$ Department of Finance, Stephen Ross School of Business, University of Michigan, Ann Arbor, MI 48109, email: rdittmar@umich.edu
} 


\section{Introduction}

The investment-based model of asset pricing introduced in Cochrane (1991) has been instrumental in shaping our understanding of the relation between firms' investment decisions and the expected returns on their equity. Perhaps the most prominent application of the framework has been in showing that a production-based model generates variation in expected returns correlated with observable characteristics such as the book-to-market ratio. In particular, Zhang (2005) shows that in a neoclassical framework with a reduced-form stochastic discount factor with time-varying risk premium, firms' optimal investment choices in the face of costs to adjustment of capital result in book-to-market effects. More specifically, since value firms are less flexible than growth firms in their ability to reduce capital stock in bad economic times, value firms are riskier than growth firms and earn a higher unconditional equity premium. Thus, the explanatory power of book-tomarket for cross-sectional variation in expected returns, brought to prominence in Fama and French (1992), can be justified through firms' rational behavior in the face of asymmetric adjustment costs to capital. ${ }^{1}$

While the neoclassical model generates a value premium, there is little evidence on whether the value premium that we observe is consistent with the mechanism implied by the model. The reason that the value premium emerges is because value firms are riskier than growth firms. In the context of the neoclassical model, this means that the return on investment of value firms covaries more negatively with an equilibrium stochastic discount factor than the return on investment of growth firms. While this prediction is at the core of the investment-based pricing model, the empirical literature investigating the relation between an investment-based model and the value premium has focused on indirect implications of the model. For example, Xing (2008), following the observation in Zhang (2005) that there is a one-to-one correspondence between investment growth and bookto-market ratio, shows that an investment growth factor explains the value effect and the pricing of the Fama and French (1993) high-minus-low factor. Similarly, Chen, Novy-Marx, and Zhang (2010) form investment-based factors and show that these factors perform better at explaining a wider array of anomalies than the factors in Fama and French (1993). However, neither of these papers provide evidence that their factors generate differences in the risk of investment returns as implied by the neoclassical model.

Our goal in this paper is to investigate the connection between the risk embodied in firms' investment decisions, their expected equity returns, and the value premium. Specifically, we address the following issues. We first ask whether a stochastic discount factor that is in the linear span

\footnotetext{
${ }^{1}$ Alternative explanations for the value premium have been advanced in an investment-based framework. In particular, Berk, Green, and Naik (1999), Cooper (2006), and Carlson, Fisher, and Giammarino (2004) develop investmentbased models that generate book-to-market effects. Zhang (2005) emphasizes that these models exogenously specify quantities that are endogenous in his neoclassical framework, particularly firm-level project and systematic risk.
} 
of investment returns can jointly satisfy optimality of investment and explain expected returns across portfolios sorted on firms' book-to-market ratios. Given this stochastic discount factor, we analyze whether value firms appear to be in fact riskier than growth firms. We then consider as an alternative a stochastic discount factor that is in the linear span of equity returns. Again, we ask whether this stochastic discount factor implies optimality of investment and whether differences in risk of investment returns relative to this discount factor explain differences in expected returns across value and growth firms.

The tests that we perform in our paper, together with the conclusions that we draw from their results, depend critically on the specification of a stochastic discount factor. While specifying a stochastic discount factor is an inescapable necessity of investigating the performance of an asset pricing model, it also poses a joint hypothesis problem. ${ }^{2}$ If we reject the implications of the model, specifically the implication that investment is optimal relative to the stochastic discount factor, it is unclear whether investment is sub-optimal or that we are using a stochastic discount factor that is mis-specified from the perspective of the firm. That is, if we find that the risk of the return on investment of value firms is not greater than that of growth firms, it is unclear whether this conclusion is being drawn because we have incorrectly measured risk.

To ameliorate the concern of stochastic discount factor mis-specification, we consider minimal restrictions on the stochastic discount factor. In particular, following Hansen and Jagannathan (1991), we simply assume that the stochastic discount factor is in the linear span of payoffs. Under the condition of no arbitrage, this stochastic discount factor will exist and will satisfy the Euler equations implied by optimal investment. We consider two alternatives; first, that the stochastic discount factor is in the linear span of investment returns and second, that the stochastic discount factor is in the linear span of equity returns. While this stochastic discount factor has limited economic content, as it does not identify the primitive source of risk or how preferences determine investors' risk-return tradeoff, it has the advantage of being minimally restrictive. It is difficult to argue that the investment-based model is well-specified if a stochastic discount factor in the linear span of investment returns cannot explain the returns to assets' equity.

Our results provide mixed support for, but generally evidence against the ability of the investmentbased model to explain differences in expected returns across book-to-market-sorted portfolios. When the stochastic discount factor is modeled as lying in the linear span of investment returns, we find that overidentifying restrictions implied by Euler equations for equity and investment returns, are strongly rejected with large pricing errors. The model fails to capture more than a small portion of the value premium. Further investigation reveals that it is not because the model fails

\footnotetext{
${ }^{2}$ Liu, Whited, and Zhang (2009) claim to test the implications of the model in the absence of a stochastic discount factor. However, as we discuss below, their test amounts to a test of linear homogeneity, rather than a test of the pricing implications of the investment-based model. More specifically, the restrictions they test can hold even when the investment-based model is mis-specified.
} 
to deliver differences in risk across assets. Value firms do indeed appear to be riskier than growth firms, exhibiting larger (negative) covariances with the stochastic discount factor. The failure of the model lies in the inability to generate a sufficiently large premium for this risk when confronted by both the investment and equity return data.

Several earlier papers empirically investigate the implications of investment Euler equations for cross-sectional variation in returns. Our approach is closely related to Cochrane (1996) and Gomes, Yaron, and Zhang (2006), who investigate investment Euler equations' implications for expected equity returns. Cochrane (1996), uses investment returns as factors, and investigates the ability of a stochastic discount factor that is a linear function of investment returns to price a set of size-sorted portfolios. He finds that the model performs about as well as the CAPM or the Chen, Roll, and Ross (1986) factor model in explaining cross-sectional variation in returns on these portfolios. Gomes, Yaron, and Zhang (2006) pursue a similar exercise in investigating the role financial frictions play in explaining cross-sectional variation in returns. Our approach differs significantly from theirs in that we construct our investment returns from firm characteristics, following Liu, Whited, and Zhang (2009), rather than aggregate macroeconomic data. Our focus is also explicitly on the role that optimal investment plays in understanding the value premium across firms.

Also closely related is Liu, Whited, and Zhang (2009), who investigate the minimal restrictions implied in the Euler equation for firms' investment decisions. The authors assume that investment decisions are optimal, and estimate production parameters by matching means and variances of implied investment returns to means and variances of equity returns. We take a similar approach, but employ the pricing restrictions implicit in the return covariance with a stochastic discount factor. As we note, only by incorporating a stochastic discount factor can one infer whether the production-based model can explain expected returns across assets. If the Euler equation for investment does not hold, implying Euler equation errors in investment, matching means of investment and equity returns merely implies that equity returns also inherit the same average Euler equation errors. Since a voluminous literature (see, e.g. Whited (1998)) documents violations of investment Euler equations at the firm level, this concern is particularly relevant for evaluating the empirical performance of production-based asset pricing models.

The remainder of the paper is organized as follows. In Section 2, we briefly review the production-based asset pricing framework that underlies our empirical analysis. In Section 3, we discuss our empirical implementation. Section 4 examines the performance of the productionbased model in explaining returns to value-sorted portfolios and analyzes the sources of the model's success and failure. Concluding comments are presented in Section 5. 


\section{Production-Based Pricing and the Cross-Section of Returns}

We begin by discussing the theoretical framework linking investment returns to expected equity returns. The model that we present is a fairly standard neoclassical model of optimal firm investment, following in the steps of Cochrane (1991). However, as noted by Zhang (2005), in order to generate a value premium, introducing frictions such as costly reversibility of investment is necessary. Thus, the model incorporates this feature and follows Liu, Whited, and Zhang (2009) in terms of characterizing equilibrium asset prices.

\subsection{Firm Value Maximization}

Because the investment-based model is now standard in the literature, we skip over a number of the formal assumptions and proceed directly to firms' choice problem; for details on the assumptions please see, for example, Liu, Whited, and Zhang (2009). Firms choose investment and debt to maximize the present value of the expected future cash flows paid to investors. These cash flows are operating profits, which are assumed to be optimized relative to costlessly adjustable inputs, net of capital expenditures, debt payments, and taxes. More specifically, firms solve the problem

$$
\max _{I_{i, t+s}, K_{i, t+s+1} B_{i, t+s+1}, \forall s} V_{i t} \equiv E_{t}\left[\sum_{s=0}^{\infty} M_{t+s} D_{i, t+s}\right]
$$

where

$$
D_{i, t}=\left(1-\tau_{t}\right)\left[\Pi\left(K_{i t}, Z_{i t}\right)-\Phi\left(I_{i t}, K_{i t}\right)\right]-I_{i t}+B_{i t+1}-R_{i t}^{B} B_{i t}+\tau_{t} \delta_{i t} K_{i t}+\tau_{t}\left(R_{i t}^{B}-1\right) B_{i t}
$$

is the dividend payout of the firm at time $t$. In this expression, $K_{i t}$ is the capital stock of the firm at time $t, Z_{i t}$ is a technology shock, $I_{i t}$ is investment in new capital, $B_{i t}$ is the stock of one-period debt, $r_{i t}^{B}$ is the rate of interest paid on the debt, $\tau_{t}$ is the corporate tax rate, and $\delta_{i t}$ is the rate of depreciation of the capital stock. The functions $\Pi\left(K_{i t}, Z_{i t}\right)$ and $\Phi\left(I_{i t}, K_{i t}\right)$ represent the optimized operating profit function and adjustment cost of capital function, respectively.

The interpretation of equation (2) is straightforward. Increasing dividends are net-of-tax operating profits, $\left(1-\tau_{t}\right) \Pi\left(K_{i t}, Z_{i t}\right)$, new debt issues, $B_{i t+1}$, and the depreciation and interest tax shields, $\tau_{t} \delta_{i t} K_{i t}+\tau_{t}\left(R_{i t}^{B}-1\right) B_{i t}$. Reducing dividends are investment, $I_{t}$, net-of-tax costs of adjusting investment, $\left(1-\tau_{t}\right) \Phi\left(I_{i t}, K_{i t}\right)$, and interest payments on existing debt, $R_{i t}^{B} B_{i t}$. As in Liu, Whited, and Zhang (2009), we assume that the production function, $\Pi\left(K_{i t}, Z_{i t}\right)$, is a CobbDouglas function with constant returns to scale. The constant returns to scale assumption means 
that $\Pi\left(K_{i t}, Z_{i t}\right)=K_{i t} \partial \Pi\left(K_{i t}, Z_{i t}\right) / \partial K_{i t}$. The adjustment cost function is given by

$$
\Phi\left(I_{i t}, K_{i t}\right)=\frac{a}{2}\left(\frac{I_{i t}}{K_{i t}}\right)^{2} K_{i t}
$$

with $a>0$.

In choosing investment, firms face a tradeoff. Investing results in increased capital being deployed, and since operating profits are constant returns to scale, this means that investing results in higher future dividend payments, increasing firm value, ceteris paribus. However, investment is costly, both through the actual cost of the capital itself, $I_{i t}$, but also through costs of adjustment. Typical costs of adjustment include notions of downtime, retooling, and training on new equipment. Firms invest until the marginal benefit from a dollar of new investment offsets its marginal cost. That is, firms invest until the present value of investing an additional dollar in capital, marginal $q$, equals the marginal cost. At this level of investment, firms are in equilbrium.

\subsection{Equilibrium and Expected Equity Returns}

As discussed above, at an interior optimum, firms invest to the point where the marginal benefit of investing an additional dollar is offset by the cost. This means choosing an investment plan to maximize the present value of the stream of future dividends. Discounting is achieved as shown in equation (1) using a stochastic discount factor, $M_{t}$, that is determined outside of the model. The assumption is that $M_{t}$ represents investors intertemporal marginal rate of substitution. For example, if investors have time-separable utility as in Lucas (1978), the stochastic discount factor is given by

$$
M_{t+s}=\beta^{s} \frac{U^{\prime}\left(C_{t+s}\right)}{U^{\prime}\left(C_{t}\right)}
$$

where $\beta$ is a rate of time preference. The specific form is not typically assumed; rather, it is simply assumed that some market clearing equilibrium in the market for financial assets determines $M_{t+s}$.

Given the stochastic discount factor, the first order condition for firms' optimization with respect to investment can be expressed as

$$
E_{t}\left[M_{t+1} R_{i, t+1}^{I}\right]=1
$$

where $R_{i, t+1}^{I}$ is the return on investment, given by

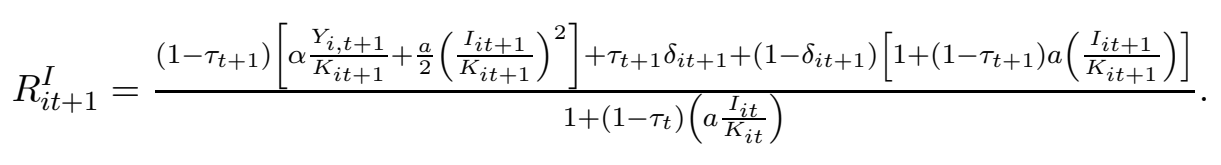

As shown in (5), the return on investment, and thus the Euler equation, is determined by a set of 
observable (to the level of proxies) firm characteristics. Specifically, a firm's return on investment and Euler equation can be expressed as a function of the ratio of output to capital and investment to capital. As shown in Zhang (2005), this Euler equation implies that expected returns will be related to ratios of the book value of a firm's equity to its market value in the cross-section.

The implications of this expression for risk premia in the cross section are a bit more transparent from rewriting the Euler equation in terms of expected risk premium. Equation (5) implies that the risk premium associated with the return on investment for firm $i$ is given by

$$
\begin{aligned}
& E_{t}\left[R_{i t+1}^{I}\right]-R_{f, t}=-\frac{\operatorname{Cov}_{t}\left(M_{t+1}, R_{i t+1}^{I}\right)}{E_{t}\left[M_{t+1}\right]}
\end{aligned}
$$

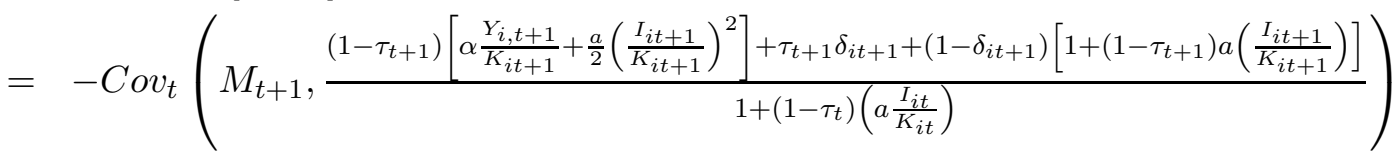

$$
\begin{aligned}
& \times\left(1+R_{f, t}\right)
\end{aligned}
$$

The expression clarifies the types of firms that we expect will have higher risk premium. Holding the denominator fixed, if a firm's profitability per unit of capital $\left(Y_{i, t+1} / K_{i, t+1}\right)$ covaries strongly with the stochastic discount factor, it will tend to have a lower risk premium. Since the stochastic discount factor is expected to be large in bad states, the equation implies that a firm with strong cash flows in these states will require a lower risk premium. Similarly, if the marginal reduction in adjustment costs, $\frac{a}{2}\left(I_{i t+1} / K_{i t+1}\right)$ covaries strongly with bad states of the world, adjusting the capital stock will be cheaper in these states, resulting in a lower risk premium.

The connection to equity returns can be drawn through the properties of the production and adjustment cost functions. As noted in Cochrane (1991), without leverage, equity returns are directly proportional to investment returns. With leverage and linear homogeneity of the production and adjustment cost functions, Liu, Whited, and Zhang (2009) show that equity returns are related to investment returns by

$$
R_{i t+1}^{S}=\frac{R_{i, t+1}^{I}-w_{i t} R_{i t+1}^{B a}}{1-w_{i t}},
$$

where $R_{i, t+1}^{B a}=R_{i, t+1}^{B}\left(1-\tau_{t}\right)+\tau_{t}$ and $w_{i t}$ represents market leverage. Thus, equity returns are positively related to investment returns, and the intuition for sources of increased investment return premia translate to increased equity return premia. In particular, if value firms have poorer marginal profitability per unit of capital and greater adjustment costs in bad economic times, they will earn a premium to growth firms, as noted in Zhang (2005).

Equation (6) holds if firms invest optimally; this is the restriction tested in Liu, Whited, and Zhang (2009). However, in the appendix, we show that this relation, which we refer to as the weighted average cost of capital (WACC), can hold when firms invest suboptimally (relative to this 
base case) as well. This consideration is especially relevant in the face of the large corporate finance literature that suggests that firms invest suboptimally. Thus, testing whether WACC holds does not constitute a test of optimality of investment, and thus of the implications of the investment-based model. Optimality requires that the Euler equation, equation (4), holds, and thus that investors require higher premia for firms with greater risk, embodied in the covariance of the assets' payoffs with the stochastic discount factor.

\section{Empirical Implementation}

\subsection{Testable Restrictions}

We exploit three restrictions implied by the model in our estimation. While these restrictions do not exhaust the implications of the model, they are the most relevant for understanding the pricing of equity securities.

\section{Restriction 1: Optimal Investment}

At the core of the investment pricing model is the assumption that firms invest optimally - the tradeoffs that firms face in determining optimal investment result in firm characteristics relation to average equity returns. This restriction has been tested extensively at the firm level (see Whited (1998) and references therein), where it has widely been rejected. It is possible, however, that the condition may hold at the portfolio level, as noise in the estimation of firm-specific Euler equations is canceled out across portfolios. Estimation of this restriction requires the specification of a stochastic discount factor, $\hat{M}_{t+1}$, and the empirical analogue to the Euler equation,

$$
\frac{1}{T} \sum_{t=1}^{T} \mathbf{u}_{t}=\frac{1}{T} \sum_{t=1}^{T} \hat{M}_{t} \mathbf{R}_{t}^{I}-\mathbf{1}_{N}=0
$$

where $T$ is the number of time series observations, $\mathbf{R}_{t}^{I}$ is a vector of investment returns defined in (5), and $\mathbf{1}_{N}$ is a conforming vector of ones. The parameters of the stochastic discount factor, as well as the production parameters $a$ and $\alpha$ can be estimated via GMM. Under the null of optimal investment, the Hansen (1982) $J$-test will suggest rejection of the model.

\section{Restriction 2: Optimal Investment and Pricing of Equity Returns}

Under the $q$ theory of investment, firms optimize their investment decisions by maximizing the present discounted value of the firms dividends, discounting relative to the stochastic discount factor, $M_{t}$. This same discount factor also prices the firm's equity. Thus, again, given a candidate 
stochastic discount factor, $\hat{M}_{t+1}$, the $q$ theory implies

$$
\frac{1}{T} \sum_{t=1}^{T} \mathbf{v}_{t}=\frac{1}{T} \sum_{t=1}^{T} \hat{M}_{t} \mathbf{R}_{t}^{S}-\mathbf{1}_{N}=0 .
$$

To investigate whether the $q$ theory explains the equity returns, it necessary that (7) hold empirically. Thus, the restrictions implied by (8) should be explored either subsequent to, or in conjunction with the estimation of the stochastic discount factor parameters that explain investment returns. Alternatively, one could estimate parameters of the stochastic discount factor under the restrictions in (8), and use the resulting stochastic discount to examine whether firms are investing optimally.

Restriction 3: Equity Returns are Related to Investment Returns by WACC

Equity and investment returns are linked by a form of the weighted average cost of capital. Strictly speaking, this restriction is supposed to hold in each state of the world. However, as noted in Liu, Whited, and Zhang (2009), imposing the restriction in this manner is likely to provide too stringent a test of the model in the face of observed data. Consequently, the restriction is tested in expectation instead,

$$
\frac{1}{T} \sum_{t=1}^{T} \mathbf{e}_{t}=\frac{1}{T} \sum_{t=1}^{T}\left(\mathbf{R}_{t}^{S}-\frac{\mathbf{R}_{t}^{I}-\mathbf{w}_{t-1} \cdot \mathbf{R}_{t}^{B}}{1-\mathbf{w}_{t-1}}\right)=0
$$

where $\mathbf{R}_{t}^{B}$ is a vector of debt returns and $\mathbf{w}_{t-1}$ is beginning-of-period leverage. As we discuss above and in the appendix, rejection of this restriction suggests that linear homogeneity of the production and adjustment cost functions are violated. If rejected, the rejection does not indicate an invalidation of the investment-based model, but rather the particular functional form assumed. Similarly, failure to reject does not indicate optimality of investment, and thus the validity of the model.

As is evident from above, the restrictions can easily be expressed as moment conditions in a generalized method of moments (GMM) estimation; consequently, we estimate parameters and test model specification using GMM. A remaining issue is the specification of the stochastic discount factor. Although a number of candidate stochastic discount factors have been proposed in the literature, a consensus as to its specification remains lacking. We discuss the specification of the stochastic discount factor in the next section. 


\subsection{Empirical Specification of the Stochastic Discount Factor}

The previous section discusses restrictions on the joint pricing of investment and stock returns under particular specifications of the stochastic discount factor. In this section, we discuss two empirical approaches that we pursue to define the stochastic discount factor.

Stochastic Discount Factor in the Linear Span of Investment Returns

At the core of the investment-based pricing model is the assumption that investment is optimal. A natural point of departure for empirical investigation, therefore, is to investigate a stochastic discount factor designed to satisfy optimal investment. Hansen and Jagannathan (1991) propose a diagnostic for dynamic asset pricing models and accompanying technique for recovering a stochastic discount factor that satisfies an Euler equation exactly by projecting the stochastic discount factor onto the space of returns;

$$
E\left[\mathbf{R}_{t+1}^{I} \mathbf{R}_{t+1}^{I \prime} \boldsymbol{\delta}\right]=\mathbf{1}
$$

The equation states that the minimum variance stochastic discount factor that lies in the linear

span of investment returns can be constructed by the sample analogue of $\boldsymbol{\delta}=E\left[\mathbf{R}_{t+1}^{I} \mathbf{R}_{t+1}^{I \prime}\right]^{-1} \mathbf{1}$. In principle, given a set of investment returns, one can construct a stochastic discount factor that exactly satisfies optimal investment.

While equation (11) holds in principle, given the law of one price, In practice, however, optimality cannot be imposed on the stochastic discount factor in the linear span, because investment returns depend on the unknown parameters $a$ and $\alpha$. In order to identify these parameters, we must provide restrictions to identify them or hold the parameters fixed. The Euler equations for equity returns, the empirical analogue of which is in equation (8), provide identification of these parameters, and the empirical weighted average cost of capital equation, expression (9), provides additional identification as shown in Liu, Whited, and Zhang (2009).

An issue that arises in this context is that the investment return parameters $a$ and $\alpha$ affect only the mean and the standard deviation of the investment returns, and not the covariances with any of the other variables. Cochrane (1996) notes this difficulty and the resulting bad behavior of the minimization problem. In particular, he notes the presence of a "valley" in the minimization surface that causes the gradient matrix to be singular. He carefully chooses the parameters as fixed in order to circumvent this problem. In our context, we achieve identification via the weighted average cost of capital equations, which are used to pin down the mean of the investment returns.

Stochastic Discount Factor in the Linear Span of Equity Returns

An alternative approach is to allow the stochastic discount factor to be projected onto the space of equity returns. That is, we alternatively assume that the stochastic discount factor is a linear 
combination of the equity payoffs:

$$
E\left[\mathbf{R}_{t+1}^{S} \mathbf{R}_{t+1}^{S \prime} \boldsymbol{\delta}\right]=\mathbf{1}
$$

where $\boldsymbol{\delta}=E\left[\mathbf{R}_{t+1}^{S} \mathbf{R}_{t+1}^{S \prime}\right]^{-1} \mathbf{1}$. In this case, the stochastic discount factor can, in principle, be directly estimated without imposing overidentifying restrictions to estimate production parameters. Alternatively, as in Chen and Knez (1996), the parameters can be estimated jointly with production parameters by including overidentifying restrictions implied by equation (7), equation (9), or both. We pursue the latter approach and estimate the production parameters and SDF parameters jointly.

Our interpretation of tests of the model under this stochastic discount factor is slightly different than the discount factor implied by investment returns. In this case, we do not impose optimal investment, but do impose no arbitrage in the equity market. Given the equivalence of no arbitrage and equilibrium as shown in Harrison and Kreps (1979), one can interpret the tests as asking whether, observing equilibrium in the equity market, firms optimize investment relative to the stochastic discount factor implied by the equity market. In this sense, tests of overidentifying restrictions implied by this stochastic discount factor represent tests of the hypothesis of optimal investment in the face of equity market equilibrium rather than whether optimal investment implies equity market equilibrium.

The stochastic discount factors as specified in the linear span of investment or equity returns are akin to asking whether one set of assets spans the other set of assets. DeSantis (1995) and Bekaert and Urias (1996) investigate whether one set of assets can span another by exploiting similar conditions to those that we investigate in testing the investment-based model. Thus, the empirical results that we report can be viewed as providing insight in the ability of investment returns to span equity returns and vice versa. Cochrane (2001) discusses the links between the Hansen and Jagannathan (1991) bounds and these tests at great length.

\section{Parametric Stochastic Discount Factor}

While stochastic discount factors in the linear span of equity or investment returns are very flexible and general, Cochrane (2001) notes that they have limited economic interpretation. An alternative is to use a stochastic discount factor motivated by a model of investor preferences, such as the consumption CAPM. However, it is already well-documented (see, e.g. Liu, Whited, and Zhang (2009)) that the consumption CAPM, and even a more ad hoc factor model such as the Fama and French (1993) three-factor model are rejected by the overidentifying restrictions implied by the Euler equation for stock returns. The use of the stochastic discount factors presented in this section give maximum benefit to the investment-based model in explaining returns. They ask simply whether, given either optimal investment or the law of one price in the equity market, expected returns can be explained by the risk in investment returns. Nonetheless, to investigate the robustness of our results, we also examine a stochastic discount factor implied by the Fama 
and French (1993) three-factor model:

$$
M_{t+1}=\delta_{0}+\delta_{M R P} R_{M R P, t+1}+\delta_{S M B} R_{S M B, t+1}+\delta_{H M L} R_{H M L, t+1}
$$

where $R_{M R P, t+1}$ is the return on the market portfolio in excess of the risk free rate, $R_{S M B, t+1}$ is the return on a small market capitalization portfolio in excess of a large market capitalization portfolio, and $R_{H M L, t+1}$ is the return on a high book-to-market portfolio in excess of the return on a low book-to-market portfolio.

Because the factors in this case are linear combinations of the returns on a set of portfolios, we expect that the results will be similar to those obtained by investigating a stochastic discount factor in the linear span of equity returns. The two will not be exactly comparable, since the factors are linear combinations of portfolios defined over a coarser space (book-to-market tercile portfolios) and alternative characteristics (size portfolios separated on the median). However, like the equity stochastic discount factor, the Fama and French (1993) stochastic discount factor is a linear combination of the underlying equity returns and may, as a result, generate similar conclusions.

\section{Empirical Results}

\subsection{Data}

We closely follow Liu, Whited, and Zhang (2009) in the data that we use in empirical estimation. Since the focus of much of the investment-based pricing literature is on explaining book-to-market effects, we utilize 10 portfolios sorted on the basis of their book-to-market-ratios at the end of June of each calendar year. Book-to-market ratios are calculated following Davis, Fama, and French (2000). A firm's book value is calculated using the most recent fiscal year end data, where the most recent fiscal year ends in the prior calendar year. Book value is defined as stockholder's equity plus deferred taxes and investment tax credits, less preferred stock. Book value is defined as shareholder's equity (COMPUSTAT Item SEQ), common equity (COMPUSTAT item CEQ), or the difference in total assets (AT) and total liabilities (LT), in order of preference. Preferred stock is the redemption value of preferred stock (PRSTKRV) or liquidation value (PSTKL), in order of preference. The book-to-market ratio is then computed as the ratio of this book value to market value from CRSP at the end of the preceding December. Firms are ranked into deciles on the basis of NYSE breakpoints.

The investment return is a function of a number of firm-specific variables, most specifically

output, investment, capital, depreciation, taxes, and the return on bonds. As in Liu, Whited, and 
Zhang (2009), we measure output, $Y_{i t}$ as net sales (SALEQ), capital stock, $K_{i t}$, as gross property, plant, and equipment (PPEGQ), debt, $B_{i t}$ as total long term debt (DLTTQ), and depreciation, $\delta_{i t}$, as total depreciation and amortization (DPQ) divided by the capital stock. Capital expenditures are measured as quarterly capital expenditures; for second through fourth fiscal quarters, the capital expenditures are measured as the first difference in the year-to-date capital expenditures (CAPXY), net of the first difference in year-to-date sales of assets (SPPEY). ${ }^{3}$ Investment sales are assumed to be zero if the data are missing. Finally, the return on bonds, $r_{i t}^{B}$, is measured as interest expense (XINTQ) divided by average debt over the period. Debt is measured as total long term debt (DLTTQ) plus short term debt (DLCQ). Tax rates are measured using statutory tax rates. ${ }^{4}$ We eliminate firms with quarter ends that do not correspond to calendar quarters, and firms for whom data on capital or sales are unavailable.

In our tests, we face a significant tradeoff between the time span of the data and the frequency of the data. Liu, Whited, and Zhang (2009) use annual data, permitting a time span of 59 annual observations if all available data are used. In contrast, due to availability of the capital expenditures data, our data span is limited to the period starting at the end of 1983, or 105 quarterly observations. Our fear is that an estimation with 59 time series observations will be lacking in power, and that the covariance matrix needed to estimate the stochastic discount factor will be poorly estimated. In our opinion, the increased precision of estimates, particularly of second moments, from a finer data sampling and greater number of observations outweighs the consideration of a longer economic timespan.

Our timing convention for matching returns and accounting data differ from that in Liu, Whited, and Zhang (2009). They match annual returns from July of year $t$ through June of year $t+1$ to stock variables measured at December of year $t-1$ and December of year $t$ and flow variables at December of year $t$. We speculate that this convention was chosen in part due to the timing mismatch between the Fama and French (1992) procedure for calculating book-to-market ratios and annual returns, and in part due to allowing time for accounting information to be disclosed. In our opinion, the timing of the accounting returns should match the timing of stock returns. Return on investment is based on economic information that is available to managers at a given time period, and returns to equities are determined by investors' expectations of this information. Further, we use finer (quarterly) data in our tests, as we speculate that, given the variability in returns, that a test using annual returns will have low power. The timing of book-to-market classification is irrelevant to quarterly returns, and the timing of the availability of quarterly information to investors is unclear.

\footnotetext{
${ }^{3}$ We experimented with alternative definitions of investment including the change in gross property, plant, and equipment and the change in total assets, net of change in current assets. We found that the resulting investment quantities appeared to be very large, averaging in some cases over $50 \%$ of total capital.

${ }^{4}$ We thank Laura Liu for making these data available on her web page.
} 
We report summary statistics for the returns and accounting variables for the accounting information in Table 1. The value effect is strong in these data, with high book-to-market firms earning returns that are $4.362 \%$ per quarter higher on average than low book-to-market firms. The magnitude of the effect is similar to that in Liu, Whited, and Zhang (2009); despite the different time period, our results are consistent with their annual average premium of $17.1 \%$. In our sample, total return volatility is somewhat higher for the high book-to-market firms, but in general there is little relation across the deciles between book-to-market ratio and return volatility.

Our data on accounting variables are also consistent with those reported in Liu, Whited, and Zhang (2009). Ratios are computed by summing the numerator and denominator independently across firms, and then performing division. The average investment to capital ratio $(\overline{I / K})$ is generally decreasing in the book-to-market ratio, with growth firms investing more than value firms. When annualized, these flow numbers are similar to those reported in earlier work. The same is true for output to capital $(\overline{Y / K})$, which is also decreasing in the book-to-market decile, with a small uptick for high book-to-market firms. High book-to-market firms also exhibit higher market leverage $(\bar{w})$ than low book-to-market firms. In general, the summary statistics point to effects documented earlier in the literature; value firms earn higher returns, invest less, experience lower output per unit of capital, and are more highly levered.

\subsection{Implications of Optimal Investment for Expected Equity Returns}

In Table 2, we present parameter estimates and specification tests for the case in which the stochastic discount factor is assumed to be in the linear span of investment returns. Point estimates and the specification test are presented in Panel A and the Euler equation errors are presented in Panel B. As shown in the table, the point estimate of the share of capital in the production function $(\alpha=0.103)$ is considerably smaller than that in previous literature of approximately 0.3 (e.g. Rotemberg and Woodford $(1992))$, but is precisely estimated $(S E=0.011)$. In contrast, the point estimate of the adjustment cost parameter $(a=0.046)$ is considerably smaller in magnitude than that estimated in Liu, Whited, and Zhang (2009) and estimated with substantial imprecision $(S E=0.146)$. These differences likely manifest themselves because returns on investment are nonlinear functions of the ratios of flow variables (e.g. investment) to stock variables (e.g. capital).

The specification test for the model suggests that the restrictions implied by the Euler equations for investment and equity returns are strongly rejected. The overidentifying restrictions test $\left(\chi_{9}^{2}=\right.$ $46.572)$ rejects the null at less than the $1 \%$ significance level $(p$-value $=0.000)$. Further insight into the rejection is presented in Panel B of Table 2. While the model captures the pricing of growth firms quite well, with a pricing error of -5 basis points per quarter, the point estimates of pricing errors for value firm returns are large and statistically significant. Pricing errors increase nearly 
monotonically over the book-to-market deciles, peaking at $4.21 \%$ per quarter for the value portfolio. These pricing errors are statistically significant at conventional (5\% critical value) significance for the seventh through tenth decile of book-to-market. The value premium in excess of that implied by the model is $17.04 \%$ per annum, only marginally smaller than the $17.45 \%$ per annum premium in the raw data of Table 1.

By construction, the stochastic discount factor prices investment returns reasonably well. As shown in the table, the Euler equation errors range from $-1.033 \%$ for the seventh decile portfolio to $0.384 \%$ for the first decile portfolio. None of these Euler equation errors can be statistically distinguished from zero at the $5 \%$ level. Thus, the investment Euler equations appear to be statistically satisfied for the book-to-market sorted portfolios, but this optimality does not seem to imply that equity returns can be explained by the risk inherent in investment returns.

In Table 3, we repeat the estimation, but impose 10 additional moment conditions, as in Liu, Whited, and Zhang (2009). That is, we require that the weighted average cost of capital hold for the assets, in addition to the Euler equations for investment and stock returns. Our hope is that imposing these conditions will help us better identify the parameters of the investmentbased model. As shown in the table, we improve the precision of the estimation of the adjustment cost parameter $(a=3.033, S E=0.444)$, and obtain a point estimate that is similar to that in Liu, Whited, and Zhang (2009), accounting for their use of annual rather than quarterly data. The investment share is approximately the same as in our earlier estimation $(\alpha=0.132)$ ), and is statistically distinguishable from zero at the $10 \%$ significance level $(S E=0.069)$.

Despite the improved precision, the qualitative conclusions of our tests are largely unchanged. The model remains rejected at high levels of statistical significance $\left(\chi_{19}^{2}=65.325, p\right.$-value $\left.=0.000\right)$. The pricing errors, however, are improved; as shown in Panel B, the low book-to-market portfolio has an equity Euler equation error of $-0.819 \%$ while the high book-to-market portfolio has an equity Euler equation error of $3.330 \%$. Only the Euler equation error for the high book-to-market portfolio is statistically distinguishable from zero at the $5 \%$ level. While this result represents an improvement over our earlier estimates, it continues to imply a large unexplained value premium in excess of $16 \%$ per annum.

The results presented in this section are discouraging for the investment-based pricing model. While the model seems to be a theoretical success, generating a value premium consistent with that observed in the data, its empirical performance is decidedly weaker. The results of this section indicate that a stochastic discount factor in the linear span of investment returns cannot explain cross-sectional differences in the expected returns on book-to-market-sorted portfolios. In the next section, we analyze the implied investment returns more closely in an attempt to better understand the sources of the investment-based model's failure. 


\subsection{Investment Returns and Risk of Value and Growth Portfolios}

In Table 4, we present means and standard deviations of the returns on investment for the 10 bookto-market-sorted portfolios. Investment returns are calculated using the parameters estimated in Table 3, using the WACC restrictions in addition to Euler equation restrictions for stock and investment returns. In addition, we present risk exposures from regressing equity returns on the stochastic discount factor implied by the estimation:

$$
R_{i, t}=\alpha+\beta_{i} M_{t}+\epsilon_{i, t}
$$

with accompanying standard errors in parentheses.

As shown in the table, investment returns are generally decreasing across book-to-market deciles. The lowest (growth) book-to-market portfolio has a mean investment return of $3.51 \%$, implying a premium of $2.20 \%$ over the mean return on the highest (value) book-to-market portfolio of $1.31 \%$. This premium is about half the size of the $4.36 \%$ premium in equity returns. The returns are also substantially less volatile than the equity returns. For example, while the standard deviation of the top book-to-market portfolio equity return is $16.73 \%$, that of the investment return is only $4.95 \%$. This result is consistent with Cochrane (1991), who finds that investment returns are only about $60 \%$ as volatile as equity returns.

When we calculate betas of equity returns with respect to the stochastic discount factor implied by investment returns, we observe a strong relation between book-to-market equity decile, average equity return, and risk exposure to the stochastic discount factor. As shown in the table, the high book-to-market portfolio has the largest in magnitude negative exposure to the stochastic discount factor $\beta_{i}=-1.56$ and the lowest has the smallest in magnitude negative exposure $\left(\beta_{i}=-0.55\right)$. Since risk premia are negatively associated with covariance with the stochastic discount factor, the estimates suggest that we should expect a higher premium on value firms than growth firms. Stated differently, the parameter estimates indicate that value (growth) firms' equity returns are relatively high (low) when the realization of the stochastic discount factor is low, and relatively low (high) when the realization of the stochastic discount factor is high. That is, value firms have relatively poorer payoffs in bad economic times than good economic times compared to growth firms.

These results stand in stark contrast to the GMM tests conducted in the previous section; they suggest that investment returns do a good job of explaining differences in risk exposures across book-to-market-sorted portfolios. In unreported tests, we find that a cross-sectional regression of average returns on the risk exposures do generate a statistically significant risk premium with an adjusted $R^{2}$ in excess of $60 \%$. We do not tabulate these results due to the small cross-section, but do note that they suggest that average returns on the book-to-market sorted portfolios appear to 
be related to exposures to the risks inherent in investment returns.

Why then do the GMM results indicate strong failure for the model with large pricing errors? To gain further insight into this question, we depict the Hansen and Jagannathan (1991) bounds on admissible stochastic discount factors in Figure 1. We plot two sets of bounds; one set for the investment returns and one set for the equity returns augmented by the 3-month T-Bill return. Additionally, we plot the locus of the estimated stochastic discount factor in mean-variance space. As shown in the figure, the volatility of the estimated stochastic discount factor is quite low; on the scale of the graph, it is difficult to distinguish from zero.

The Hansen-Jagannathan bounds suggest that the reason that the model fails to explain the equity returns is that the stochastic discount factor implied by the model is insufficiently volatile. Through the duality of the bounds and the mean-variance efficient frontier, this also suggests that the stochastic discount factor cannot generate a sufficiently large Sharpe ratio to explain the equity returns. Put differently, while the model suggests that differences in risk across the equity returns relative to the stochastic discount factor correlate with average returns, the model cannot generate a sufficiently large risk premium to explain the equity returns.

Another noteworthy point from the figure is that the stochastic discount factor estimated using Euler equation restrictions for both equity and investment returns also plots far from the HansenJagannathan bounds for the investment returns. The implication of this result is that some tension between equity and investment returns prevents the stochastic discount factor that best satisfies Euler equations for both equity and investment returns to satisfy the bounds for investment returns. To get some insight into what this tension might be, we construct the stochastic discount factor in the linear span of investment returns that satisfies the Euler equations for investment exactly, as implied in equation (14). The investment-based model predicts that it is this stochastic discount factor that should best explain equity returns, since optimality of investment links book-to-market ratios to expected equity returns.

Analogous to our earlier results, we calculate Euler equation errors and risk exposures for the equity returns relative to this stochastic discount factor. We present the results of this analysis in Table 5. As shown in the table, this stochastic discount factor generates large positive Euler equation errors. Errors range from $1.32 \%$ per quarter on average for the low book-to-market portfolio to $5.31 \%$ per quarter for the high book-to-market portfolio. The value spread in average returns generated by the constructed stochastic discount factor is quite similar to the magnitude generated by the estimated stochastic discount factor. The Hansen and Jagannathan (1997) distance of the estimated stochastic discount factor (0.5605) is marginally lower than that of the constructed discount factor (0.5654). A stark difference emerges, however, when analyzing risk measures. As shown in the table, there is virtually no dispersion in exposures to the risk inherent in the con- 
structed discount factor across book-to-market deciles. Thus, risk in a stochastic discount factor that satisfies optimal investment exactly does not generate differences of risk across portfolios that generates the spread in value and growth average returns.

The results in this section provide important insight into the failings of the production-based model. The results suggest that a stochastic discount factor that exactly satisfies optimality of investment in sample cannot generate dispersions in risk consistent with the expected returns across book-to-market-sorted portfolios. In order to generate these risks, the stochastic discount factor must strike something of a compromise. It can generate risk dispersion, but it cannot generate a sufficiently large risk premium to explain differences in risk across book-to-market-sorted portfolios. As a result, the stochastic discount factor generates large pricing errors and fails to explain crosssectional differences in equity returns.

\subsection{Is Investment Optimal Given the Information in Equity Returns?}

In the previous sections, we ask whether risk and risk premia inherent in investment returns can explain cross-sectional variation in expected equity returns. That is, we allow the stochastic discount factor to be defined as a linear function of investment returns and ask whether this stochastic discount factor can explain equity returns. In this section, we turn the question around and ask whether investment seems to be optimal given the information in equity returns. The major difference in this section is that we allow the stochastic discount factor to be linear in the payoffs to equity rather than the payoff to investment. We estimate the model using only Euler equations for investment and equity returns and then add the restrictions implied by the weighted average cost of capital to improve identification of the production parameters.

Results imposing only Euler equation restrictions are presented in Table 6. As shown, the estimates of the production parameters are similar to those estimated earlier, but considerably more precise. The point estimate of capital share in the production function is somewhat lower but similar to the estimate obtained using an investment-based stochastic discount factor $(\alpha=$ $0.072, S E=0.026)$. The adjustment costs parameter $(a=3.317, S E=0.242)$ is quite similar to the earlier estimate. Like the earlier estimation, the model is strongly rejected in the data, as indicated by the specification test. The overidentifying restrictions test $\left(\chi_{9}^{2}=36.988\right)$ rejects at the $1 \%$ level of significance. We interpret this rejection as suggesting that, conditional on equilibrium in the equity market, firms do not invest in an optimal manner, at least relative to the objective function implied by the constraints explored in this paper.

The Euler equation errors, shown in Panel B of Table 6 suggest the source of model failure. The equity-implied stochastic discount factor performs quite poorly in explaining both equity returns and investment returns. Despite the fact that the Euler equation is linear in equity returns, pricing 
errors for equity are large, ranging from $-2.24 \%$ per quarter for the low book-to-market portfolio to $-3.21 \%$ for the ninth decile book-to-market portfolio. Similarly, investment appears far from optimal, with Euler equation errors ranging from $-2.31 \%$ for the eighth decile book-to-market portfolio to $3.15 \%$ for the tenth decile portfolio. While none of these Euler equation errors are estimated precisely, the magnitude is sufficiently large (the mean absolute error is 2.675) to drive rejection of the model.

When we incorporate the restrictions implied by the weighted average cost of capital, the performance of the model deteriorates even further. Model parameter estimates and specification test results are presented in Table 7. Rather than improving the ability to estimate the production parameters as in the earlier section, the fit deteriorates, with the production share remaining relatively similar in magnitude $(\alpha=0.122)$, but poorly estimated $(S E=0.092)$. The adjustment cost parameter is estimated to be somewhat lower $(a=0.840)$, but again is imprecisely estimated. The restrictions implied by the model are strongly rejected; the $\chi_{18}^{2}$ test statistic of 67.529 implies rejection of the model at greater than the $1 \%$ significance level.

While the specification tests results are not unlike those reported when the stochastic discount factor is linear in the investment returns, the model fit is dramatically worse. In attempting to satisfy the WACC restrictions in addition to the Euler equation restrictions, the model performs extremely poorly in attempting to fit investment and equity returns. The mean absolute error across all Euler equations is $11.40 \%$. These errors are smallest for the WACC restrictions (m.a.e = $2.37 \%$ ), but are extremely large for the investment returns (m.a.e. $=15.37 \%)$ and equity returns $(m . a . e=16.06 \%)$. As shown in Panel B, not only are the errors large, but they are all statistically significant as well. Thus, in contrast to the case in which the SDF is linear in investment returns, imposing WACC restrictions result in a dramatic deterioration in model fit.

As noted, the deterioration in the model is due to the difficulty in fitting the mean and standard deviation of the returns on investment, implied by the WACC restrictions, while fitting the mean, standard deviation, and covariance structure of the equity returns. We pursue one final alternative. We allow the Euler equations to be satisfied exactly in the equity market, and consider the implications for investment and weighted average cost of capital. That is, we specify the stochastic discount factor as

$$
\hat{M}_{t}=\hat{\boldsymbol{\delta}}^{\prime} \mathbf{R}_{t}^{S}
$$

where

$$
\hat{\boldsymbol{\delta}}=\left(\frac{1}{T} \sum_{t=1}^{T} \mathbf{R}_{t}^{S} \mathbf{R}_{t}^{S \prime}\right)^{-1} \mathbf{1}_{N}
$$

This stochastic discount factor is examined as a performance measure in Chen and Knez (1996).

Results of this estimation are presented in Table 8. Note that in this case, since the stochastic 
discount factor is specified as an exact function of the returns on the equity portfolios and risk-free asset that the only moment conditions are the Euler equations for investment and the weighted average cost of capital, and that there are only two parameters to estimate. Once again, the point estimate of the capital share in production is consistent with previous estimates and precisely estimated $(\alpha=0.133, S E=0.055)$. However, the adjustment cost parameter $(a=-0.480, S E=$ 0.332) now has a negative point estimate, although the estimate is imprecisely estimated. This somewhat puzzling result suggests adjustment benefits, rather than costs.

Regardless of the point estimates of the parameters, the model is again strongly rejected by the test of overidentifying restrictions $\left(\chi_{18}^{2}=72.746, p=(0.000)\right)$. Again, the point estimates of the equation errors in Panel B suggest why. Investment does not appear to be optimal under this stochastic discount factor, with all investment Euler equation errors greater than zero. The errors range from $0.67 \%$ per quarter for the ninth decile portfolio to $2.83 \%$ per quarter for the bottom decile portfolio. While the standard errors are large, the model has difficulty simultaneously capturing the WACC conditions. Low book-to-market portfolios tend to have negative WACC errors, as suggested by the bottom book-to-market decile portfolio error of $-2.50 \%$ per quarter $(S E=1.20)$, and high book-to-market portfolios tend to have positive WACC errors, as suggested by the eighth decile error of $2.30 \%$ per quarter $(S E=1.20)$.

The conclusion from this section is that, again, the model has difficulty capturing the information in both equity and investment returns simultaneously. When free to choose, the estimates seem to emphasize the WACC restrictions, resulting in large pricing errors for both equity and investment returns. When the law of one price is imposed in the equity market, the model fails to capture means of investment returns through the WACC restrictions, and produces economically significant Euler equation errors for investment. Thus, the results suggest that, given the information in the equity returns, investment does not appear to be optimal for the book-to-market-sorted portfolios.

\subsection{Robustness Checks}

In the preceding sections, we present evidence that suggests that the investment-based model has a difficult time explaining returns on portfolios sorted on the book-to-market ratio. The principal reason appears to be the fact that, when investment returns are used to form the stochastic discount factor, the model is not able to generate a sufficiently large risk premium and still attempt to satisfy Euler equations for returns on equity and returns on investment. When equity returns are used to extract the stochastic discount factor, it appears investment is sub-optimal, in contradiction to the core predictions of the investment-based model.

In this section, we briefly discuss a few robustness checks that we examine to substantiate the 
findings of the previous sections. We focus on two issues. First, in our tests we include the risk free rate as either a test asset or a component of the stochastic discount factor. Cochrane (2001) notes that GMM may attempt to overfit the moment condition on the risk free rate, whereas Farnsworth, Ferson, Jackson, and Todd (2002) note that without some discipline on the mean of the stochastic discount factor, the implied tangency portfolio can be on the bottom portion of the efficient frontier. The second issue is the specification of the discount factor.

\section{Inclusion of the Risk Free Rate}

As mentioned previously, including the risk free rate trades off imposing more reasonable restrictions on the discount factor with focusing too much on fitting the moment conditions related to the risk-free asset. We consider two alternatives to address these concerns. The first involves testing using excess returns:

$$
\begin{aligned}
E\left[M_{t}\left(R_{t}^{I}-R_{f, t}\right)\right] & =0 \\
E\left[M_{t}\left(R_{t}^{S}-R_{f, . t}\right)\right] & =0 \\
1-\delta^{\prime}\left(R_{t}^{I}-\bar{R}^{I}\right) & =M_{t}
\end{aligned}
$$

This estimation imposes a unit mean on the stochastic discount factor. The second alternative is to omit the risk-free asset altogether. For brevity, we report tables using the excess returns condition. Results omitting the risk free asset but using gross returns are qualitatively similar and are available from the authors upon request.

In Table 9, we present results of this estimation, including conditions for the weighted average cost of capital to improve the precision of estimates. ${ }^{5}$ We note two key points. First, pricing errors remain large, but are somewhat reduced. The Euler equation error for the top decile portfolio falls to $2.15 \%$ per quarter and the bottom decile to $-1.72 \%$ per quarter, implying an annual premium in excess of $15 \%$. While smaller than in the case with gross returns, this quantity is still quite large. None of the individual Euler equation errors can be distinguished from zero, but that the errors are jointly significant, as the model is rejected at more than the $1 \%$ significance level as indicated by the $J$-test $\left(\chi_{18}^{2}=60.473\right)$.

The second point is that the model estimates a negative adjustment cost parameter under excess returns. The capital share in production $(\alpha=0.132)$ is precisely estimated $(S E=0.015)$ and is similar in magnitude the estimates we obtain throughout the paper. However, while the adjustment cost parameter $(a=-0.459)$ is precisely estimated $(S E=0.089)$, the negative coefficient is economically confounding. Explanations for adjustment costs generally focus on investment being costly due to retooling and downtime; this parameter estimate suggests some benefit to adjustment.

\footnotetext{
${ }^{5}$ Similar results with less precisely estimated parameters are obtained omitting the WACC restriction. Results are available on request.
} 
Our conclusion from these tables is that while using excess returns improves the fit of the model slightly, this benefit is outweighed by the economically counterintuitive parameter estimates.

\section{Alternative Stochastic Discount Factors}

Liu, Whited, and Zhang (2009) investigate the performance of the CAPM and Consumption CAPM (CCAPM) stochastic discount factors in pricing these equity returns and find that the models are strongly rejected. We repeat their estimation, since we are using somewhat different timing conventions and a different data frequency, but confirm their results. In our sample and for our data, neither the CAPM nor the CCAPM performs well in satisfying Euler equations for investment and equity returns. It is difficult to directly compare these results to those presented earlier in the paper because the models are not nested. However, when we impose the Euler equation restrictions for both equity and investment returns and the weighted average cost of capital condition, we find that the value spread indicated by the Euler equation errors is nearly $17 \%$ per annum for both models. For brevity, and since these results are reported in Liu, Whited, and Zhang (2009), we do not tabulate these results.

As discussed above, we do examine one parametric alternative, the Fama and French (1993) three-factor stochastic discount factor, as in equation (12). This stochastic discount factor incorporates a market, size, and book-to-market factor since the results of Fama and French (1992) indicate that size and book-to-market describe the majority of cross-sectional variation in average returns. Factor returns are taken from Ken French's website; variable construction is detailed in Fama and French (1993). ${ }^{6}$

Results of this estimation are reported in Table 10. Perhaps not surprisingly, the results are quite similar to those reported in Table 7, when the stochastic discount factor is in the linear span of equity returns. Point estimates of the capital share $(\alpha=0.126)$ and adjustment cost parameter $(a=0.696)$ are of similar magnitude, and are imprecisely estimated. The only price of risk that enters statistically significantly into the stochastic discount factor is that of the HML factor; the negative sign on the risk price $(\delta H M L=-9.826)$ indicates that assets earn a premium for bearing HML risk. As above, the model is strongly rejected by the test of overidentifying restrictions, and the mean absolute error is large.

As above, the model has considerable difficulty simultaneously satisfying the weighted average cost of capital restriction and the Euler equations for stock and investment returns. The pricing errors for both investment and stock returns are uniformly negative and large in magnitude. None of the errors are statistically significant individually, but the omnibus test statistic suggests that they are statistically significantly different than zero in aggregate. The source of the model's failure in this case is in emphasizing fitting the WACC restrictions at the cost of violating the Euler

\footnotetext{
${ }^{6}$ We would like to thank Ken French for making these data available.
} 
equations.

\section{Conclusion}

In this paper, we estimate parameters and test restrictions implied by the investment-based pricing model in the context of book-to-market-sorted portfolio returns. Our investigation follows the work of Cochrane (1991), who suggests the investment-based model as an alternative to consumptionbased models for understanding asset prices. More specifically, our paper empirically investigates the conclusions of Zhang (2005), who shows that in the context of optimal investment with adjustment costs to investment, that firm's investment decisions imply that book-to-market ratios will be positively correlated with expected returns. We test the Euler equations implied by optimal investment and equity market equilibrium to obtain implications for expected equity returns.

Our results suggest that the restrictions implied by the investment-based model do not hold in the cross-section of book-to-market-sorted stock returns. When we allow the stochastic discount factor to be in the linear span of investment returns, the model produces equity Euler equation errors that are both economically large and statistically significant. Thus, a stochastic discount factor that seems to satisfy firms' first order conditions for optimal investment does not appear to be able to explain differences in expected returns across stocks. Additionally, specifying the stochastic discount factor as linear in equity returns, thus satisfying Euler equations for equities appears to imply suboptimal investment. Consequently, we come to the conclusion that the investment-based model does not explain cross-sectional variation in equity returns.

However, we do find evidence supportive of one of the key intuitions of the investment-based model. When we fit the stochastic discount factor as linear in investment returns, we find that the equity returns of value firms covary more strongly negatively with the stochastic discount factor than those of growth firms. Since we expect firms with more negative covariance with the stochastic discount factor to earn higher risk premia due to increased risk, this result is consistent with the idea that value firms are riskier than growth firms, as suggested by the investment-based model. The difficulty the model faces is in generating a sufficiently volatile stochastic discount factor, or large enough premium for these risks, to justify the magnitude of the equity return premium in value firms relative to growth firms.

Further, it is possible that extensions to the investment-based model may generate implications that are consistent with the equity returns of book-to-market-sorted portfolios. In particular, a large body of literature examines the role that financing frictions play in generating cross-sectional variation in equity returns, including Lamont, Polk, and Saá-Requejo (2001), Gomes, Yaron, and Zhang (2006), and Whited and Wu (2006). Since this explanation is at the core of explanation 
for firm-level violations of investment Euler equations, as in Hubbard and Kashyap (1992) and Hubbard, Kashyap, and Whited (1995), it may help to explain why a model with fewer frictions has difficulty when confronted with the cross-section of book-to-market-sorted portfolio returns. 


\section{Appendix}

In their Proposition 1, Liu, Whited, and Zhang (2009) show that optimal investment implies that the investment return is a linear combination of the after-tax corporate bond return and the equity return:

$$
R_{i, t+1}^{I}=w_{i, t} R_{i, t+1}^{B a}+\left(1-w_{i, t}\right) R_{i, t+1}^{S}
$$

where $R_{i, t+1}^{B a}$ is the after-tax corporate bond return, $R_{i, t+1}^{S}$ is the equity return, and $w_{i, t+1}$ is market leverage, the ratio of market value of debt to market value of assets. In this appendix, we show that this equality holds when investment is sub-optimal relative to the case when adjustment costs provide the only friction in firms' investment decisions.

Assume that investors do not invest optimally, and, as a result, the first order conditions for firms' optimization problem do not hold with equality. We do not make any assumptions as to the source of the suboptimal investment; suboptimal investment might arise due to frictions or violation of rational expectations. Firms' first order conditions become

$$
\begin{aligned}
q_{i t} & <1+\left(1-\tau_{t}\right) \Phi_{i, I, t+1} \\
q_{i t} & <E_{t}\left[M_{t+1}\left\{\left(1-\tau_{t+1}\right)\left[\Pi_{i, K, t+1}-\Phi_{i, K, t+1}\right]+\tau_{t+1} \delta_{i, t+1}+\left(1-\delta_{i, t+1}\right) q_{i, t+1}\right\}\right] \\
1 & =E_{t}\left[M_{t+1}\left\{r_{i, t+1}^{B}-\left(r_{i, t+1}^{B}-1\right) \tau_{t+1}\right\}\right] .
\end{aligned}
$$

In these expressions, $\Phi_{i, I, t+1}$ is shorthand for the partial derivative of the adjustment cost function with respect to investment, $\Phi_{i, K, t+1}$ is the partial derivative of the adjustment cost function with respect to capital, and $\Pi_{i, K, t+1}$ is the partial derivative of the output function with respect to capital.

We next assume that there is some variable, $\xi_{i, t}$, that will make the inequalities above equalities. We assume that the variable affects the Euler equations such that

$$
\begin{aligned}
q_{i t}+\xi_{i t}= & 1+\left(1-\tau_{t}\right) \Phi_{i, I, t+1} \\
q_{i t}+\xi_{i t}= & E_{t}\left[M _ { t + 1 } \left\{\left(1-\tau_{t+1}\right)\left[\Pi_{i, K, t+1}-\Phi_{i, K, t+1}\right]+\tau_{t+1} \delta_{i, t+1}\right.\right. \\
& \left.\left.+\left(1-\delta_{i, t+1}\right)\left(q_{i, t+1}+\xi_{i, t+1}\right)\right\}\right] \\
1= & E_{t}\left[M_{t+1}\left\{r_{i, t+1}^{B}-\left(r_{i, t+1}^{B}-1\right) \tau_{t+1}\right\}\right]
\end{aligned}
$$

Note that under this specification, the return on (suboptimal) investment is given by

$$
R_{t+1}^{I}=\frac{\left(1-\tau_{t+1}\right)\left[\Pi_{K, t+1}-\Phi_{K, t+1}\right]+\tau_{t+1} \delta_{t+1}+\left(1-\delta_{t+1}\right)\left(q_{t+1}+\xi_{t+1}\right)}{q_{t}+\xi_{t}},
$$

where we suppress firm-specific subscripts $i$ going forward for convenience. 
We wish to show in this setting that equation (A1) continues to hold. We proceed following Liu, Whited, and Zhang (2009). Denote the price of a claim to equity as $P_{i, t}$ and the cum-dividend value of equity $V_{i, t}=P_{i, t}+D_{i, t}$. The firm's optimization target and the definition of dividends result in the following expression:

$$
\begin{aligned}
V_{i t}= & \left(1-\tau_{t}\right)\left[\Pi_{t}-\Phi_{t}\right]-I_{t}+B_{t+1}-r_{t}^{B} B_{t}+\tau_{t} \delta_{t} K_{t}+\tau_{t}\left(r_{t}^{B}-1\right) B_{t}+ \\
& E_{t}\left[\sum _ { j = 1 } ^ { \infty } M _ { t + j } \left(\left(1-\tau_{t+j}\right)\left[\Pi_{t+j}-\Phi_{t+j}\right]-I_{t+j}-\tau_{t+j} B_{t+j}+B_{t+j+1}-r_{t+j}^{B} B_{t+j}\right.\right. \\
& \left.\left.+\tau_{t+j} \delta_{t j} K_{t+j}+\tau_{t+j}\left(r_{t+j}^{B}-1\right) B_{t+j}\right)\right]
\end{aligned}
$$

where we have suppressed firm-specific subscripts, $i$ for notational simplicity, let $\Pi_{t+j}=\Pi\left(K_{t+j}, X_{t+j}\right)$, and let $\Phi_{t+j}=\Phi\left(K_{t+j}, I_{t+j}\right)$. This quantity can be equivalently expressed as

$$
\begin{aligned}
V_{t}= & P_{t}+\left(1-\tau_{t}\right)\left[\Pi_{t}-\Phi_{t}\right]-I_{t}+B_{t+1}-r^{B} B_{t}+\tau_{t} \delta_{t} K_{t}+\tau_{t}\left(r_{t}^{B}-1\right) B_{t} \\
= & \left(1-\tau_{t}\right)\left[\Pi_{t}-\Phi_{I_{t}} I_{t}-\Phi_{K_{t}} K_{t}-r_{t}^{B} B_{t}\right]-I_{t}-\tau_{t} B_{t}+B_{t+1}+\tau_{t} \delta_{t} K_{t} \\
& -\left(q_{t}+\xi_{t}\right)\left[K_{t+1}-\left(1-\delta_{t}\right) K_{t}-I_{t}\right] \\
& +E_{t}\left[\sum _ { j = 1 } ^ { \infty } M _ { t + j } \left[\left(1-\tau_{t+j}\right)\left[\Pi_{t+j}-\Phi_{I_{t+j}} I_{t+j}-\Phi_{K_{t+j}} K_{t+j}-r_{t+j}^{B} B_{t+j}\right]-I_{t+j}-\tau_{t+j} B_{t+j}\right.\right. \\
& \left.\left.+B_{t+j+1}+\tau_{t+j} \delta_{t+j} K_{t+j}-\left(q_{t+j+1}+\xi_{t+j+1}\right)\left[K_{t+j+1}-\left(1-\delta_{t+j}\right) K_{t+j}-I_{t+j}\right]\right]\right] .
\end{aligned}
$$

We recursively substitute equations (A2), (A3), and (A4) and simplify to obtain

$$
\begin{aligned}
V_{t} & =P_{t}+\left(1-\tau_{t}\right)\left[\Pi_{t}-\Phi_{t}-R_{t}^{B} B_{t}\right]-\tau_{t} B_{t}-I_{t}+B_{t+1}+\tau_{t} \delta_{t} K_{t} \\
& =\left(1-\tau_{t}\right)\left[\Pi_{t}-\Phi_{K_{t}} K_{t}-R_{t}^{B} B_{t}\right]-\tau_{t} B_{t}+\left(q_{t}+\xi_{t}\right)\left(1-\delta_{t}\right) K_{t}+\tau_{t} \delta_{t} K_{t}
\end{aligned}
$$

Linear homogeneity of the adjustment cost function implies that

$$
\begin{aligned}
V_{t} & =P_{t}+B_{t+1} \\
& =\left(1-\tau_{t}\right) \Phi_{I, t}+I_{t}+\left(q_{t}+\xi_{t}\right)\left(1-\delta_{t}\right) K_{t} \\
& =\left(q_{t}+\xi_{t}\right) I_{t}+\left(q_{t}+\xi_{t}\right)\left(1-\delta_{t}\right) K_{t} \\
& =\left(q_{t}+\xi_{t}\right)\left(I_{t}+\left(1-\delta_{t}\right) K_{t}\right)=\left(q_{t}+\xi_{t}\right) K_{t+1} .
\end{aligned}
$$


The proof of equation (A1) follows by noting that

$$
\begin{aligned}
& w_{t} R_{t+1}^{B a}+\left(1-w_{t}\right) R_{t+1}^{S} \\
= & \frac{\left(1-\tau_{t+1}\right) R_{t+1}^{B} B_{t+1}+\tau_{t+1} B_{t+1}+P_{t+1}+D_{t+1}}{P_{i t}+B_{i t}} \\
= & \frac{P_{i, t+1}+B_{i, t+2}+\left(1-\tau_{t+1}\right)\left[\Pi_{t+1}-\Phi_{t+1}\right]-I_{t+1}+\tau_{t+1} \delta_{t+1} K_{t+1}}{P_{i t}+B_{i t+1}} \\
= & \frac{\left(q_{t+1}+\xi_{t+1}\right) K_{t+2}+\left(1-\tau_{t+1}\right)\left(\Pi_{K, t+1}-\Phi_{K, t+1}\right) K_{t+1}-\left(q_{t+1}+\xi_{t+1}\right) I_{t+1}+\tau_{t+1} \delta_{t+1}}{\left(q_{t}+\xi_{t}\right) K_{t+1}} \\
= & \frac{\left(q_{t+1}+\xi_{t+1}\right)\left(1-\delta_{t+1}\right)+\left(1-\tau_{t+1}\right)\left(\Pi_{K, t+1}-\Phi_{K, t+1}\right)-\xi_{t+1} I_{t+1}+\tau_{t+1} \delta_{t+1}}{q_{t}+\xi_{t}} \\
= & R_{t+1}^{I} .
\end{aligned}
$$




\section{References}

Bekaert, Geert, and Michael Urias, 1996, Diversification, integration, and emerging market closedend funds, Journal of Finance 51, 835-869.

Berk, Jonathan, Richard Green, and Vasant Naik, 1999, Optimal investment, growth options and security returns, Journal of Finance 54, 1553-1607.

Carlson, Murray, Adlai Fisher, and Ron Giammarino, 2004, Corporate investment and asset price dynamics: Implications for the cross-section of returns, Journal of Finance 59, 2577-2603.

Chen, Long, Robert Novy-Marx, and Lu Zhang, 2010, An alternative three-factor model, unpublished manuscript, Ohio State University.

Chen, Nai-Fu, Richard Roll, and Stephen A Ross, 1986, Economic forces and the stock market, Journal of Business 59, 383-403.

Chen, Zhiwu, and Peter Knez, 1996, Portfolio performance measurement: Theory and applications, Review of Financial Studies 9, 507-551.

Cochrane, John, 1991, Production-based asset pricing and the link between stock returns and economic fluctuations, Journal of Finance 46, 209-237.

— 1996, A cross-sectional test of an investment-based asset pricing model, Journal of Political Economy 104, 572-621.

— 2001, Asset Pricing (Princeton University Press: Princeton, NJ).

Cooper, Ilan, 2006, Asset pricing implications of nonconvex adjustment costs and irreversibility of investment, Journal of Finance 61, 139-170.

Davis, James L, Eugene F Fama, and Kenneth R French, 2000, Characteristics, covariances, and average returns: 1929-1997, Journal of Finance 55, 389-406.

DeSantis, George, 1995, Volatility bounds for stochastic discount factors: Tests and implications from international financial markets, unpublished manuscript, University of Southern California.

Fama, Eugene F., and Kenneth R. French, 1992, The cross-section of expected stock returns, Journal of Finance 47, 427-465.

— 1993, Common risk factors in the returns on stocks and bonds, Journal of Financial Economics 33. 
Farnsworth, Heber, Wayne Ferson, David Jackson, and Steven Todd, 2002, Performance evaluation with stochastic discount factors, Journal of Business 75, 473-504.

Gomes, Jo ao, Amir Yaron, and Lu Zhang, 2006, Asset pricing implications of firms' financing constraints, Review of Financial Studies 19, 1322-1356.

Hansen, Lars Peter, 1982, Large sample properties of generalized method of moments estimators, Econometrica 40, 1029-1054.

— , and Ravi Jagannathan, 1991, Implications of security market data for models of dynamic economies, Journal of Political Economy 99, 225-262.

— 1997 , Assessing errors in stochastic discount factor models, Journal of Finance 52, 557590.

Harrison, J, and D Kreps, 1979, Martingales and arbitrage in multiperiod securities markets, Journal of Economic Theory 20, 381-408.

Hubbard, Glenn R., and Anil K. Kashyap, 1992, Internal net worth and the investment process: an application of u.s. agriculture, Journal of Political Economy 100, 506-534.

— , and Toni M. Whited, 1995, Internal finance and firm investment, Journal of Money, Credit, and Banking 27, 683-701.

Lamont, Owen A, Christopher Polk, and Jesus Saá-Requejo, 2001, Financial constraints and stock returns, Review of Financial Studies 14, 529-554.

Liu, Laura Xiaolei, Toni M. Whited, and Lu Zhang, 2009, Investment-based expected stock returns, Journal of Political Economy 117, 1105-1139.

Lucas, Robert, 1978, Asset prices in an exchange economy, Econometrica 46, 1429-1445.

Rotemberg, Julio J., and Michael Woodford, 1992, Oligopolistic pricing and the effects of aggregate demand on economic activity, Journal of Political Economy 100, 1153-1207.

Whited, Toni M., 1998, Why do investment euler equations fail?, Journal of Business and Economic Statistics 16, 469-478.

— , and Guojun Wu, 2006, Financial constraints risk, Review of Financial Studies 19, 531-559.

Xing, Yuhang, 2008, Interpreting the value effect through the q-theory: An empirical investigation, Review of Financial Studies 21, 1767-1795.

Zhang, Lu, 2005, The value premium, Journal of Finance 60, 67-104. 


\section{Table 1: Summary Statistics}

Table 1 presents summary statistics for ten portfolios sorted on the basis of book-to-market ratios. Each June, firms are assigned to deciles on the basis of their book-to-market ratios, using NYSE breakpoints to determine deciles. The table reports the mean and standard deviation of returns, $\bar{r}^{S}$ and $\sigma^{r^{S}}$. Additionally, the table reports averages of characteristics that enter into the calculation of the return on investment: the investment to capital ratio, $\overline{I / K}$, output to capital, $\overline{Y / K}$, depreciation rate, $\bar{\delta}$, leverage, $\bar{w}$, and the required return on debt, $\bar{r}^{B}$. Ratios are computed by summing the numerator and denominator across firms and then performing division. Investment is capital expenditures, net of sales of assets, output is net sales, and capital is gross property, plant, and equipment. The depreciation rate is calculated as the depreciation expense divided by beginning of period capital. Required return on debt is calculated as interest expense divided by average debt outstanding over the period. Data are sampled at the quarterly frequency from the fourth quarter, 1983 through the fourth quarter, 2009.

\begin{tabular}{lrrrrrrr}
\hline \hline Decile & $\bar{r}^{S}$ & $\sigma^{r^{S}}$ & $\overline{I / K}$ & $\overline{Y / K}$ & $\bar{\delta}$ & $\bar{w}$ & $\bar{r}^{B}$ \\
\hline 1 & 2.133 & 12.154 & 4.872 & 76.454 & 3.773 & 19.495 & 3.138 \\
2 & 3.645 & 10.399 & 4.658 & 63.839 & 3.599 & 36.070 & 2.889 \\
3 & 3.559 & 10.217 & 4.009 & 52.574 & 3.043 & 36.337 & 2.917 \\
4 & 3.737 & 9.788 & 3.544 & 45.702 & 2.715 & 40.777 & 2.660 \\
5 & 3.762 & 10.172 & 3.624 & 43.735 & 2.625 & 42.454 & 2.675 \\
6 & 4.076 & 10.327 & 3.359 & 44.169 & 2.667 & 44.037 & 2.924 \\
7 & 4.431 & 11.762 & 3.057 & 41.227 & 2.492 & 45.708 & 2.987 \\
8 & 4.944 & 12.087 & 3.169 & 43.619 & 2.614 & 47.756 & 2.737 \\
9 & 4.994 & 12.570 & 2.662 & 42.862 & 2.649 & 53.056 & 2.682 \\
10 & 6.495 & 16.730 & 2.988 & 51.083 & 2.936 & 63.417 & 2.479 \\
\hline
\end{tabular}




\section{Table 2: Estimation of Euler Equations for Investment and Equity Returns}

Table 2 presents results of GMM estimation of parameters $\alpha, a$, and $\delta$ from the sample moment conditions

$$
\begin{aligned}
\frac{1}{T} \sum_{t=1}^{T} \mathbf{u}_{t} & =\frac{1}{T} \sum_{t=1}^{T} \hat{M}_{t} \mathbf{R}_{t}^{I}-\mathbf{1}_{N}=0 \\
\frac{1}{T} \sum_{t=1}^{T} \mathbf{v}_{t} & =\frac{1}{T} \sum_{t=1}^{T} \hat{M}_{t} \mathbf{R}_{t}^{S}-\mathbf{1}_{N}=0
\end{aligned}
$$

where $M_{t}=\delta^{\prime} \mathbf{R}_{t}^{I}$ and $R_{t}^{I}$ is a function of the parameters $a$ and $\alpha$ as shown in equation (5). The vector $\mathbf{R}_{t}^{S}$ is the vector of gross returns on ten book-to-market-sorted portfolios at time $t$, augmented by the return on the risk-free asset, measured as the return on three-month Treasury Bills. The table presents point estimates of the parameters $a$ and $\alpha$, the mean absolute error in the moment conditions, and the Hansen (1982) $J$-test for the null that the moment conditions are rejected. Data are sampled at the quarterly fequency from the fourth quarter, 1983, through the fourth quarter, 2009, for 105 time series observations.

Panel A: Point Estimates

\begin{tabular}{lcc}
\hline \hline & $\alpha$ & $a$ \\
\hline Estimate & 0.103 & 0.046 \\
$\mathrm{SE}$ & $(0.011)$ & $(0.146)$ \\
\hline$J$-test & 46.572 \\
d.o.f. & 9 \\
$p$-value & $(0.000)$ \\
\hline Mean Absolute Error & 1.356 \\
\hline
\end{tabular}

Panel B: Euler Equation Errors

\begin{tabular}{lrc}
\multicolumn{3}{c}{ Investment Returns } \\
\hline \hline Decile & Error & SE \\
\hline 1 & 0.384 & $(0.697)$ \\
2 & -0.316 & $(0.803)$ \\
3 & -0.661 & $(0.779)$ \\
4 & -0.886 & $(0.699)$ \\
5 & -0.966 & $(0.707)$ \\
6 & -0.960 & $(0.672)$ \\
7 & -1.033 & $(0.644)$ \\
8 & -0.947 & $(0.531)$ \\
9 & -1.030 & $(0.663)$ \\
10 & -0.686 & $(0.729)$ \\
\hline
\end{tabular}

Equity Returns

\begin{tabular}{lrc}
\hline \hline Decile & Error & SE \\
\hline 1 & -0.050 & $(1.140)$ \\
2 & 1.429 & $(0.968)$ \\
3 & 1.345 & $(0.950)$ \\
4 & 1.520 & $(0.908)$ \\
5 & 1.542 & $(0.933)$ \\
6 & 1.850 & $(0.971)$ \\
7 & 2.197 & $(1.080)$ \\
8 & 2.698 & $(1.120)$ \\
9 & 2.746 & $(1.138)$ \\
10 & 4.211 & $(1.504)$ \\
\hline
\end{tabular}




\section{Table 3: Imposing WACC Constraints}

Table 3 presents results of GMM estimation of parameters $\alpha, a$, and $\delta$ from the sample moment conditions

$$
\begin{aligned}
\frac{1}{T} \sum_{t=1}^{T} \mathbf{u}_{t} & =\frac{1}{T} \sum_{t=1}^{T} \hat{M}_{t} \mathbf{R}_{t}^{I}-\mathbf{1}_{N}=0 \\
\frac{1}{T} \sum_{t=1}^{T} \mathbf{v}_{t} & =\frac{1}{T} \sum_{t=1}^{T} \hat{M}_{t} \mathbf{R}_{t}^{S}-\mathbf{1}_{N}=0 \\
\frac{1}{T} \sum_{t=1}^{T} \mathbf{e}_{t} & =\frac{1}{T} \sum_{t=1}^{T}\left(\mathbf{R}_{t}^{S}-\frac{\mathbf{R}_{t}^{I}-\mathbf{w}_{t-1} \cdot \mathbf{R}_{t}^{B a}}{\mathbf{1}-\mathbf{w}_{t-1}}\right)=0
\end{aligned}
$$

where $M_{t}=\delta^{\prime} \mathbf{R}_{t}^{I}$ and $R_{t}^{I}$ is a function of the parameters $a$ and $\alpha$ as shown in equation (5). The vector $\mathbf{R}_{t}^{S}$ is the vector of gross returns on ten book-to-market-sorted portfolios at time $t$, augmented by the return on the risk-free asset, measured as the return on one-month Treasury Bills. $\mathbf{R}_{t}^{B a}$ is the after-tax debt return for the portfolio. The table presents point estimates of the parameters $a$ and $\alpha$, the mean absolute error in the moment conditions, and the Hansen (1982) $J$-test for the null that the moment conditions are rejected. Data are sampled at the quarterly fequency from the fourth quarter, 1983, through the fourth quarter, 2009, for 105 time series observations.

Panel A: Point Estimates

\begin{tabular}{lcc}
\hline \hline & $\alpha$ & $a$ \\
\hline Estimate & 0.132 & 3.033 \\
$\mathrm{SE}$ & $(0.069)$ & $(0.444)$ \\
\hline$J$-test & 65.325 \\
d.o.f. & 9 \\
$p$-value & $(0.000)$ \\
\hline Mean Absolute Error & 1.501 \\
\hline
\end{tabular}

Panel B: Euler Equation Errors

\begin{tabular}{lcc}
\multicolumn{3}{c}{ Investment Returns } \\
\hline \hline Decile & Error & SE \\
\hline 1 & 0.790 & $(0.671)$ \\
2 & -0.191 & $(0.777)$ \\
3 & -0.547 & $(0.757)$ \\
4 & -0.878 & $(0.684)$ \\
5 & -0.840 & $(0.694)$ \\
6 & -0.998 & $(0.656)$ \\
7 & -1.349 & $(0.631)$ \\
8 & -0.605 & $(0.517)$ \\
9 & -1.012 & $(0.665)$ \\
10 & -1.382 & $(0.713)$ \\
\hline
\end{tabular}

Equity Returns

\begin{tabular}{lrc}
\hline \hline Decile & Error & SE \\
\hline 1 & -0.819 & $(1.140)$ \\
2 & 0.646 & $(0.967)$ \\
3 & 0.565 & $(0.949)$ \\
4 & 0.737 & $(0.908)$ \\
5 & 0.753 & $(0.934)$ \\
6 & 1.079 & $(0.971)$ \\
7 & 1.405 & $(1.082)$ \\
8 & 1.901 & $(1.122)$ \\
9 & 1.918 & $(1.140)$ \\
10 & 3.330 & $(1.511)$ \\
\hline
\end{tabular}




\section{Table 4: Returns on Investment}

Table 4 presents means and standard deviations of returns on investment for ten book-to-market-sorted decile portfolios. Returns are based on parameters estimated in Table 3. The table also presents risk exposures estimated by the regression

$$
R_{i, t}^{S}=\alpha_{i}+\beta_{i} M_{t}+\epsilon_{i, t},
$$

where $M_{t}$ is the stochastic discount factor that is a linear combination of investment returns estimated via GMM as in Table 3. Standard errors of the risk exposures are reported in parentheses. Data are sampled at the quarterly fequency from the fourth quarter, 1983, through the fourth quarter, 2009, for 105 time series observations.

\begin{tabular}{lcccc}
\hline \hline Decile & Mean & Std & $\beta$ & $S E$ \\
\hline 1 & 3.513 & 3.529 & -0.548 & $(0.399)$ \\
2 & 2.495 & 4.984 & -0.600 & $(0.339)$ \\
3 & 2.141 & 4.965 & -0.565 & $(0.334)$ \\
4 & 1.828 & 4.223 & -0.579 & $(0.319)$ \\
5 & 1.874 & 4.733 & -0.669 & $(0.330)$ \\
6 & 1.721 & 3.930 & -0.440 & $(0.339)$ \\
7 & 1.375 & 3.899 & -0.649 & $(0.384)$ \\
8 & 2.169 & 2.665 & -0.676 & $(0.395)$ \\
9 & 1.736 & 5.235 & -1.036 & $(0.403)$ \\
10 & 1.313 & 4.948 & -1.564 & $(0.532)$ \\
\hline
\end{tabular}




\section{Table 5: Exact Investment-Based Stochastic Discount Factor}

Table 5 presents Euler equation errors and risk exposures for 10 book-to-market decile portfolios relative to a stochastic discount factor specified as $M_{t}^{*}=\alpha^{\prime} \mathbf{R}_{t}^{I}$, where $\alpha=E\left[\mathbf{R}_{t}^{I} \mathbf{R}_{t}^{I \prime}\right]^{-1} \mathbf{1}$. Returns on investment are based on parameters estimated in Table 3 . The pricing errors are calculated using sample moments

$$
\frac{1}{T} \sum_{t=1}^{T} \hat{M}_{t}^{*} \mathbf{R}_{t}^{S}-\mathbf{1}_{N}
$$

where $\mathbf{R}_{t}^{S}$ is a $10 \times 1$ vector of returns on book-to-market-sorted portfolios. The table presents mean pricing errors and associated standard errors, as well as risk exposures estimated by the regression

$$
R_{i, t}^{S}=\alpha_{i}+\beta_{i} M_{t}^{*}+\epsilon_{i, t},
$$

with standard errors reported in parentheses. Data are sampled at the quarterly fequency from the fourth quarter, 1983, through the fourth quarter, 2009, for 105 time series observations.

\begin{tabular}{lcccc}
\hline \hline Decile & Error & SE & $\beta$ & $S E$ \\
\hline 1 & 1.317 & $(15.216)$ & 0.023 & $(0.014)$ \\
2 & 2.041 & $(23.572)$ & 0.012 & $(0.012)$ \\
3 & 2.181 & $(25.091)$ & 0.016 & $(0.012)$ \\
4 & 2.130 & $(24.569)$ & 0.012 & $(0.011)$ \\
5 & 2.443 & $(28.063)$ & 0.017 & $(0.012)$ \\
6 & 2.611 & $(30.203)$ & 0.015 & $(0.012)$ \\
7 & 3.231 & $(36.845)$ & 0.019 & $(0.014)$ \\
8 & 3.728 & $(42.131)$ & 0.019 & $(0.014)$ \\
9 & 3.300 & $(37.333)$ & 0.012 & $(0.015)$ \\
10 & 5.310 & $(57.906)$ & 0.020 & $(0.020)$ \\
\hline
\end{tabular}




\section{Table 6: Model Estimation with Equity Return Stochastic Discount Factor}

Table 6 presents results of GMM estimation of parameters $\alpha, a$, and $\delta$ from the sample moment conditions

$$
\begin{aligned}
\frac{1}{T} \sum_{t=1}^{T} \mathbf{u}_{t} & =\frac{1}{T} \sum_{t=1}^{T} \hat{M}_{t} \mathbf{R}_{t}^{I}-\mathbf{1}_{N}=0 \\
\frac{1}{T} \sum_{t=1}^{T} \mathbf{v}_{t} & =\frac{1}{T} \sum_{t=1}^{T} \hat{M}_{t} \mathbf{R}_{t}^{S}-\mathbf{1}_{N}=0
\end{aligned}
$$

where $M_{t}=\delta^{\prime} \mathbf{R}_{t}^{S}$, and $\mathbf{R}_{t}^{S}$ is the vector of gross returns on ten book-to-market-sorted portfolios at time $t$, augmented by the return on the risk-free asset, measured as the return on three-month Treasury Bills. The vector $\mathbf{R}_{t}^{I}$ is the return on investments, as calculated in equation (5). The table presents point estimates of the parameters $a$ and $\alpha$, the mean absolute error in the moment conditions, and the Hansen (1982) J-test for the null that the moment conditions are rejected. Data are sampled at the quarterly fequency from the fourth quarter, 1983, through the fourth quarter, 2009, for 105 time series observations.

Panel A: Point Estimates

\begin{tabular}{lcc}
\hline \hline & $\alpha$ & $a$ \\
\hline Estimate & 0.072 & 3.317 \\
$\mathrm{SE}$ & $(0.026)$ & $(0.242)$ \\
\hline$J$-test & \multicolumn{2}{c}{36.988} \\
d.o.f. & 8 \\
$p$-value & $(0.000)$ \\
\hline Mean Absolute Error & 2.675 \\
\hline
\end{tabular}

Panel B: Euler Equation Errors

\begin{tabular}{lcc}
\multicolumn{3}{c}{ Investment Returns } \\
\hline \hline Decile & Error & SE \\
\hline B1 & -2.546 & $(5.765)$ \\
B2 & -2.566 & $(5.654)$ \\
B3 & -2.506 & $(5.633)$ \\
B4 & -2.587 & $(5.601)$ \\
B5 & -2.639 & $(5.605)$ \\
B6 & -2.318 & $(5.581)$ \\
B7 & -2.543 & $(5.632)$ \\
B8 & -2.311 & $(5.571)$ \\
B9 & -2.910 & $(5.582)$ \\
B10 & -3.145 & $(5.677)$ \\
\hline
\end{tabular}

Equity Returns

\begin{tabular}{lcc}
\hline Decile & Error & SE \\
\hline B1 & -2.240 & $(5.820)$ \\
B2 & -2.693 & $(5.752)$ \\
B3 & -2.861 & $(5.782)$ \\
B4 & -2.609 & $(5.798)$ \\
B5 & -2.449 & $(5.777)$ \\
B6 & -2.730 & $(5.784)$ \\
B7 & -3.137 & $(5.768)$ \\
B8 & -2.874 & $(5.764)$ \\
B9 & -3.210 & $(5.821)$ \\
B10 & -2.948 & $(5.763)$ \\
\hline
\end{tabular}


Table 7: Imposing WACC Constraints: Equity Return Stochastic Discount Factor

Table 7 presents results of GMM estimation of parameters $\alpha, a$, and $\delta$ from the sample moment conditions

$$
\begin{aligned}
\frac{1}{T} \sum_{t=1}^{T} \mathbf{u}_{t} & =\frac{1}{T} \sum_{t=1}^{T} \hat{M}_{t} \mathbf{R}_{t}^{I}-\mathbf{1}_{N}=0 \\
\frac{1}{T} \sum_{t=1}^{T} \mathbf{v}_{t} & =\frac{1}{T} \sum_{t=1}^{T} \hat{M}_{t} \mathbf{R}_{t}^{S}-\mathbf{1}_{N}=0 \\
\frac{1}{T} \sum_{t=1}^{T} \mathbf{e}_{t} & =\frac{1}{T} \sum_{t=1}^{T}\left(\mathbf{R}_{t}^{S}-\frac{\mathbf{R}_{t}^{I}-\mathbf{w}_{t-1} \cdot \mathbf{R}_{t}^{B a}}{\mathbf{1}-\mathbf{w}_{t-1}}\right)=0
\end{aligned}
$$

where $M_{t}=\delta^{\prime} \mathbf{R}_{t}^{S}$ and $R_{t}^{I}$ is a function of the parameters $a$ and $\alpha$ as shown in equation (5). The vector $\mathbf{R}_{t}^{S}$ is the vector of gross returns on ten book-to-market-sorted portfolios at time $t$, augmented by the return on the risk-free asset, measured as the return on one-month Treasury Bills. $\mathbf{R}_{t}^{B a}$ is the after-tax debt return for the portfolio. The table presents point estimates of the parameters $a$ and $\alpha$, the mean absolute error in the moment conditions, and the Hansen (1982) J-test for the null that the moment conditions are rejected. Data are sampled at the quarterly fequency from the fourth quarter, 1983, through the fourth quarter, 2009, for 105 time series observations.

Panel A: Point Estimates

\begin{tabular}{lcc}
\hline \hline & $\alpha$ & $a$ \\
\hline Estimate & 0.122 & 0.840 \\
$\mathrm{SE}$ & $(0.092)$ & $(0.582)$ \\
\hline$J$-test & 67.529 \\
d.o.f. & 18 \\
$p$-value & $(0.000)$ \\
\hline Mean Absolute Error & 11.400 \\
\hline
\end{tabular}

Panel B: Euler Equation Errors

\begin{tabular}{lrc}
\multicolumn{3}{c}{ Investment Returns } \\
\hline \hline Decile & Error & SE \\
\hline 1 & -14.910 & $(5.285)$ \\
2 & -15.676 & $(5.221)$ \\
3 & -15.999 & $(5.192)$ \\
4 & -16.234 & $(5.183)$ \\
5 & -16.242 & $(5.171)$ \\
6 & -16.286 & $(5.183)$ \\
7 & -16.476 & $(5.179)$ \\
8 & -16.303 & $(5.180)$ \\
9 & -16.371 & $(5.181)$ \\
10 & -16.124 & $(5.233)$ \\
\hline
\end{tabular}

\begin{tabular}{lrc}
\multicolumn{3}{c}{ Equity Returns } \\
\hline \hline Decile & Error & SE \\
\hline 1 & -15.682 & $(5.453)$ \\
2 & -15.534 & $(5.313)$ \\
3 & -15.417 & $(5.298)$ \\
4 & -15.323 & $(5.247)$ \\
5 & -15.302 & $(5.256)$ \\
6 & -15.060 & $(5.210)$ \\
7 & -15.289 & $(5.280)$ \\
8 & -14.955 & $(5.227)$ \\
9 & -15.139 & $(5.183)$ \\
10 & -14.672 & $(5.227)$ \\
\hline
\end{tabular}


Table 8: Exact Equity Stochastic Discount Factor

Table 8 presents results of GMM estimation of parameters $\alpha$ and $a$ from the sample moment conditions

$$
\begin{aligned}
\frac{1}{T} \sum_{t=1}^{T} \mathbf{u}_{t} & =\frac{1}{T} \sum_{t=1}^{T} \hat{M}_{t} \mathbf{R}_{t}^{I}-\mathbf{1}_{N}=0 \\
\frac{1}{T} \sum_{t=1}^{T} \mathbf{e}_{t} & =\frac{1}{T} \sum_{t=1}^{T}\left(\mathbf{R}_{t}^{S}-\frac{\mathbf{R}_{t}^{I}-\mathbf{w}_{t-1} \cdot \mathbf{R}_{t}^{B a}}{\mathbf{1}-\mathbf{w}_{t-1}}\right)=0
\end{aligned}
$$

where $\hat{M}_{t}=\boldsymbol{\delta}^{\prime} \mathbf{R}_{t}^{S}$ and $R_{t}^{I}$ is a function of the parameters $a$ and $\alpha$ as shown in equation (5). The vector $\mathbf{R}_{t}^{S}$ is the vector of gross returns on ten book-to-market-sorted portfolios at time $t$, augmented by the return on the risk-free asset, measured as the return on one-month Treasury Bills. $\mathbf{R}_{t}^{B a}$ is the after-tax debt return for the portfolio. The parameters $\boldsymbol{\delta}$ satisfy the Euler equation for equity returns in sample, such that

$$
\hat{\boldsymbol{\delta}}=\left(\frac{1}{T} \sum_{t=1}^{T} \mathbf{R}_{t}^{S} \mathbf{R}_{t}^{S \prime}\right)^{-1} \mathbf{1}_{N}
$$

The table presents point estimates of the parameters $a$ and $\alpha$, the mean absolute error in the moment conditions, and

\begin{tabular}{|c|c|c|}
\hline & $\alpha$ & $a$ \\
\hline Estimate & 0.133 & -0.480 \\
\hline $\mathrm{SE}$ & $(0.055)$ & $(0.332)$ \\
\hline$J$-test & \multicolumn{2}{|c|}{72.746} \\
\hline d.o.f. & \multirow{2}{*}{\multicolumn{2}{|c|}{$\begin{array}{c}18 \\
(0.000)\end{array}$}} \\
\hline$p$-value & & \\
\hline Mean Absolute Error & \multicolumn{2}{|c|}{1.373} \\
\hline
\end{tabular}
the Hansen (1982) $J$-test for the null that the moment conditions are rejected. Data are sampled at the quarterly fequency from the fourth quarter, 1983, through the fourth quarter, 2009, for 105 time series observations.

Panel B: Euler Equation Errors

\begin{tabular}{lcc}
\multicolumn{3}{c}{ Investment Returns } \\
\hline \hline Decile & Error & SE \\
\hline 1 & 2.831 & $(5.740)$ \\
2 & 1.850 & $(5.701)$ \\
3 & 1.350 & $(5.654)$ \\
4 & 0.873 & $(5.624)$ \\
5 & 0.723 & $(5.608)$ \\
6 & 0.881 & $(5.632)$ \\
7 & 0.723 & $(5.611)$ \\
8 & 0.694 & $(5.631)$ \\
9 & 0.672 & $(5.604)$ \\
10 & 1.257 & $(5.709)$ \\
\hline
\end{tabular}

\begin{tabular}{lcc}
\multicolumn{3}{c}{ WACC } \\
\hline \hline Decile & Error & SE \\
\hline 1 & -2.499 & $(1.197)$ \\
2 & -0.363 & $(1.030)$ \\
3 & 0.664 & $(1.108)$ \\
4 & 0.962 & $(1.005)$ \\
5 & 1.412 & $(1.133)$ \\
6 & 1.685 & $(1.145)$ \\
7 & 2.251 & $(1.163)$ \\
8 & 2.296 & $(1.201)$ \\
9 & 2.193 & $(1.491)$ \\
10 & 1.292 & $(1.786)$ \\
\hline
\end{tabular}


Table 9: Euler Equation Tests with Excess Returns

Table 9 presents results of GMM estimation of parameters $\alpha, a$, and $\delta$ from the sample moment conditions

$$
\begin{aligned}
\frac{1}{T} \sum_{t=1}^{T} \mathbf{u}_{t} & =\frac{1}{T} \sum_{t=1}^{T} \hat{M}_{t}\left(\mathbf{R}_{t}^{I}-R_{f, t} \mathbf{1}_{N}\right)=0 \\
\frac{1}{T} \sum_{t=1}^{T} \mathbf{v}_{t} & =\frac{1}{T} \sum_{t=1}^{T} \hat{M}_{t}\left(\mathbf{R}_{t}^{S}-R_{f, t} \mathbf{1}_{N}\right)=0 \\
\frac{1}{T} \sum_{t=1}^{T} \mathbf{e}_{t} & =\frac{1}{T} \sum_{t=1}^{T}\left(\mathbf{R}_{t}^{S}-\frac{\mathbf{R}_{t}^{I}-\mathbf{w}_{t-1} \cdot \mathbf{R}_{t}^{B a}}{\mathbf{1}-\mathbf{w}_{t-1}}\right)=0
\end{aligned}
$$

where $M_{t}=1-\delta^{\prime}\left(\mathbf{R}_{t}^{I}-\overline{\mathbf{R}}^{I}\right)$ and $R_{t}^{I}$ is a function of the parameters $a$ and $\alpha$ as shown in equation (5). The vector $\mathbf{R}_{t}^{S}$ is the vector of gross returns on ten book-to-market-sorted portfolios at time $t . \mathbf{R}_{t}^{B a}$ is the after-tax debt return for the portfolio. $R_{f, t}$ is the return on a three-month Treasury Bill. The table presents point estimates of the parameters $a$ and $\alpha$, the mean absolute error in the moment conditions, and the Hansen (1982) $J$-test for the null that the moment conditions are rejected. Data are sampled at the quarterly fequency from the fourth quarter, 1983, through the fourth quarter, 2009, for 105 time series observations.

Panel A: Point Estimates

\begin{tabular}{lcc}
\hline \hline & $\alpha$ & $a$ \\
\hline Estimate & 0.132 & -0.459 \\
$\mathrm{SE}$ & $(0.015)$ & $(0.089)$ \\
\hline$J$-test & 60.473 \\
d.o.f. & 18 \\
$p$-value & $(0.000)$ \\
\hline Mean Absolute Error & 1.285 \\
\hline
\end{tabular}

Panel B: Euler Equation Errors

\begin{tabular}{lrc}
\multicolumn{3}{c}{ Investment Returns } \\
\hline \hline Decile & Error & SE \\
\hline 1 & 2.233 & $(8.607)$ \\
2 & 0.841 & $(7.387)$ \\
3 & -0.716 & $(7.650)$ \\
4 & -0.190 & $(4.345)$ \\
5 & -0.102 & $(1.843)$ \\
6 & -0.555 & $(4.302)$ \\
7 & -0.615 & $(2.198)$ \\
8 & -0.333 & $(1.682)$ \\
9 & -1.227 & $(2.285)$ \\
10 & 1.073 & $(4.424)$ \\
\hline
\end{tabular}

\begin{tabular}{lrc}
\multicolumn{3}{c}{ Equity Returns } \\
\hline \hline Decile & Error & SE \\
\hline 1 & -1.718 & $(2.400)$ \\
2 & 0.217 & $(2.067)$ \\
3 & 0.557 & $(2.154)$ \\
4 & 1.044 & $(1.918)$ \\
5 & 1.061 & $(2.110)$ \\
6 & 1.962 & $(2.078)$ \\
7 & 1.411 & $(2.341)$ \\
8 & 2.743 & $(2.468)$ \\
9 & 1.768 & $(2.774)$ \\
10 & 2.152 & $(3.555)$ \\
\hline
\end{tabular}


Table 10: Euler Equation Tests with Fama-French Discount Factor

Table 10 presents results of GMM estimation of parameters $\alpha, a$, and $\delta$ from the sample moment conditions

$$
\begin{aligned}
\frac{1}{T} \sum_{t=1}^{T} \mathbf{u}_{t} & =\frac{1}{T} \sum_{t=1}^{T} \hat{M}_{t}\left(\mathbf{R}_{t}^{I}-\mathbf{1}_{N}\right)=0 \\
\frac{1}{T} \sum_{t=1}^{T} \mathbf{v}_{t} & =\frac{1}{T} \sum_{t=1}^{T} \hat{M}_{t}\left(\mathbf{R}_{t}^{S}-\mathbf{1}_{N}\right)=0 \\
\frac{1}{T} \sum_{t=1}^{T} \mathbf{e}_{t} & =\frac{1}{T} \sum_{t=1}^{T}\left(\mathbf{R}_{t}^{S}-\frac{\mathbf{R}_{t}^{I}-\mathbf{w}_{t-1} \cdot \mathbf{R}_{t}^{B a}}{\mathbf{1}-\mathbf{w}_{t-1}}\right)=0
\end{aligned}
$$

where $R_{t}^{I}$ is a function of the parameters $a$ and $\alpha$ as shown in equation (5). The vector $\mathbf{R}_{t}^{S}$ is the vector of gross returns on ten book-to-market-sorted portfolios at time $t$ augmented by the return on a three-month Treasury Bill. $\mathbf{R}_{t}^{B a}$ is the after-tax debt return for the portfolio. The stochastic discount factor is specified as

$$
M_{t}=\delta_{0}+\delta_{M R P} R_{M R P, t}+\delta_{S M B} R_{S M B, t}+\delta_{H M L} R_{H M L, t},
$$

where $R_{M R P, t}$ is the market risk premium, $R_{S M B, t}$ is the return on the "small minus big" factor and $R_{H M L, t}$ is the return on the "high book-to-market minus low book-to-market" factor as described in Fama and French (1993). The table presents point estimates of the parameters, the mean absolute error in the moment conditions, and the Hansen (1982) $J$-test for the null that the moment conditions are rejected. Data are sampled at the quarterly fequency from the fourth quarter, 1983, through the fourth quarter, 2009, for 105 time series observations.

Panel A: Point Estimates

\begin{tabular}{lcccccc}
\hline \hline & $\alpha$ & $a$ & $\delta_{0}$ & $\delta_{M R P}$ & $\delta_{S M B}$ & $\delta_{H M L}$ \\
\hline Estimate & 0.126 & 0.696 & 1.041 & 2.034 & -8.356 & -9.826 \\
$\mathrm{SE}$ & $(0.086)$ & $(0.529)$ & $(0.127)$ & $(3.475)$ & $(7.173)$ & $(2.831)$ \\
\hline$J$-test & \multicolumn{5}{c}{71.540} \\
d.o.f. & \multicolumn{7}{c}{25} \\
$p$-value & \multicolumn{7}{c}{$6.000)$} \\
\hline Mean Absolute Error & \multicolumn{7}{c}{6.490} \\
\hline
\end{tabular}

Panel B: Euler Equation Errors

\begin{tabular}{lcc}
\multicolumn{3}{c}{ Investment Returns } \\
\hline \hline Decile & Error & SE \\
\hline 1 & -8.463 & $(7.518)$ \\
2 & -8.149 & $(7.439)$ \\
3 & -8.038 & $(7.385)$ \\
4 & -8.102 & $(7.390)$ \\
5 & -8.087 & $(7.354)$ \\
6 & -8.021 & $(7.371)$ \\
7 & -7.889 & $(7.336)$ \\
8 & -7.527 & $(7.372)$ \\
9 & -7.614 & $(7.366)$ \\
10 & -6.869 & $(7.428)$ \\
\hline
\end{tabular}

\begin{tabular}{lcc}
\multicolumn{3}{c}{ Equity Returns } \\
\hline \hline Decile & Error & SE \\
\hline 1 & -7.780 & $(7.650)$ \\
2 & -8.636 & $(7.510)$ \\
3 & -9.063 & $(7.563)$ \\
4 & -9.285 & $(7.480)$ \\
5 & -9.337 & $(7.497)$ \\
6 & -9.362 & $(7.481)$ \\
7 & -9.523 & $(7.534)$ \\
8 & -9.399 & $(7.576)$ \\
9 & -9.519 & $(7.561)$ \\
10 & -9.229 & $(7.752)$ \\
\hline
\end{tabular}




\section{Figure 1: Hansen-Jagannathan (1991) Bounds on Stochastic Discount Factors}

Figure 1 presents the bounds on the stochastic discount factor of Hansen and Jagannathan (1991) implied by returns on investment and equity returns. Investment returns are returns on the investment of a set of ten book-to-marketsorted portfolios, where the investment return is defined in equation (5) with parameters estimated in Table 4 . The locus of the stochastic discount factor implied by the model estimate from Table 4 is depicted as a black point on the graph. Data are sampled at the quarterly frequency from the fourth quarter, 1983 through the fourth quarter, 2009, for 105 observations.

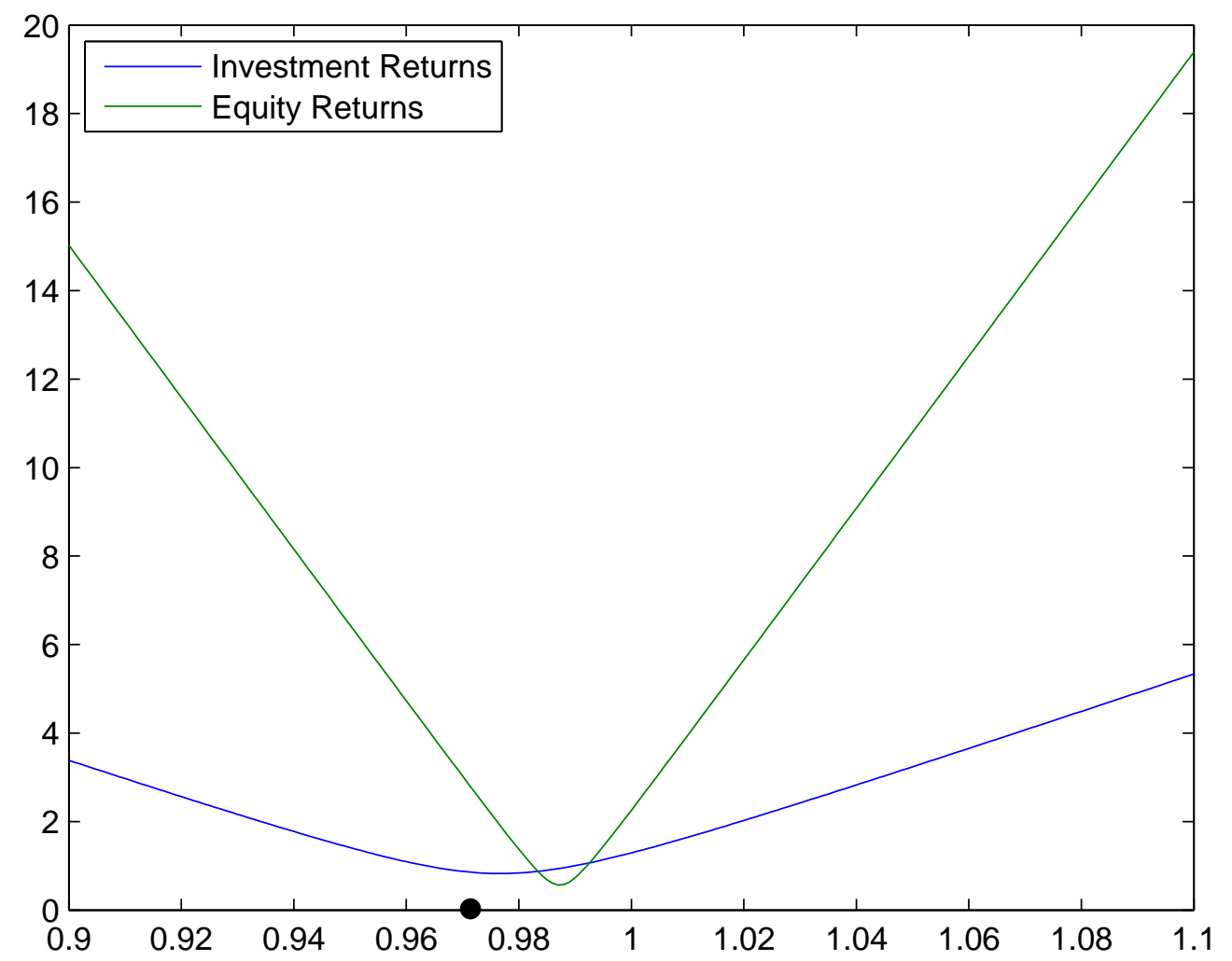

